\title{
Rotaxanes and pseudorotaxanes with threads containing viologen units
}

\author{
Malgorzata Deska, Jolanta Kozlowska, and Wanda Sliwa* \\ Jan Dlugosz University, Institute of Chemistry, Environmental Protection and Biotechnology, \\ 42-200 Czestochowa, Armii Krajowej 13/15 Street, Poland \\ E-mail: w.sliwa@ajd.czest.pl
}

\begin{abstract}
In the present review rotaxanes and pseudorotaxanes with threads containing viologen units are described. First the rotaxanes and pseudorotaxanes in which the crown ether serves as a ring are presented, they are followed by rotaxanes and pseudorotaxanes containing the crown-based cryptand as a ring. For the above interlocked species the synthetic approaches and properties, especially those promising for their use in sensors and switches are shown.
\end{abstract}

Keywords: Catenane, crown ether, cryptand, rotaxane, viologen

\section{Table of Contents}

1. Introduction

2. Rotaxanes and Pseudorotaxanes Containing Crown Ether as a Ring

2.1. Rotaxanes

2.2. Pseudorotaxanes

3. Rotaxanes and Pseudorotaxanes Containing the Crown-based Cryptand as a Ring

3.1 Rotaxanes

3.2 Pseudorotaxanes

4. Conclusions

5. Acknowledgements

6. References

\section{Introduction}

Rotaxanes ${ }^{1-5}$ and pseudorotaxanes ${ }^{6-9}$ are examples of mechanically interlocked species, ${ }^{10,11}$ besides them, to interlocked architectures belong also catenanes, ${ }^{12-15}$ as well as more complex structures such as trefoil knots, ${ }^{16}$ Solomon knots, ${ }^{17}$ Borromean rings, ${ }^{18}$ daisy chains ${ }^{19}$ or ravels. ${ }^{20}$ 
Rotaxanes are a topic of enormous number of reports due to their valuable properties, interesting in the construction of molecular machines ${ }^{21-24}$ and supramolecular polymers. ${ }^{25,26}$ Pseudorotaxanes are also intensively studied, they are prototypes of molecular machines ${ }^{27-29}$ and serve as building blocks for interlocked supramolecular assemblies, ${ }^{30}$ some of them are promising in preparation of molecular sensors ${ }^{31}$ and in drug delivery. ${ }^{32}$

There should be mentioned here also rotaxanes and pseudorotaxanes containing cyclodextrins, ${ }^{33-35}$ calixarenes ${ }^{36,37}$ or cucurbiturils. ${ }^{38,39}$

Today many works concerning viologen-based rotaxanes and pseudorotaxanes appear, ${ }^{40-45}$ in these systems viologens are components of a thread ${ }^{45-49}$ or are present as parts of the tetracationic cyclophane serving as a ring. ${ }^{50-53}$ Moreover viologens find a variety of applications due to their redox properties, they are promising for design of molecular machines and switches and construction of new materials, the rapid development of viologen chemistry has its reflection in many reports concerning these compounds. ${ }^{54-59}$

In the paper rotaxanes and pseudorotaxanes with threads containing viologen units are described. They are divided into two classes: those containing crown ether as a ring, presented in the first part, and those containing the crown-based cryptand as a ring, shown in the second part. The review is a continuation of our former papers dealing with supramolecular structures with quaternary azaaromatic character. ${ }^{40,60}$

Taking into account the great number of reports concerning rotaxanes and pseudorotaxanes with threads containing viologen units, in the review only selected examples of such species are presented.

\section{Rotaxanes and Pseudorotaxanes Containing Crown Ether as a Ring}

\subsection{Rotaxanes}

From among a great number of rotaxanes built from a thread containing viologen, and having crown ether as a ring, some examples will be presented. Design of molecular machines is today a great challenge on the scientific field, below selected works concerning this topic are described.

The operation mechanism of bistable rotaxane $\mathbf{1}^{6+}$ which acts as an molecular shuttle driven by visible light was studied by computational calculations. The shuttling free energy and shuttling relaxation time were calculated and the experimental estimations for the relative stability of the different molecular co-conformations were reproduced.

It was established that the rotaxane $\mathbf{1}^{\mathbf{6}+}$ undergoes photoinduced ring shuttling in solution, its thread contains ruthenium (II) complex $\left[\mathrm{Ru}(\mathrm{bpy})_{3}\right]^{2+}\left(\mathbf{P}^{2+}\right)$ serving as a photosensitizer and as a stopper, the second stopper is $\mathbf{T}$. The electron-accepting stations are 4,4'-bipyridinium unit, i.e. $\mathbf{V}_{\mathbf{1}}{ }^{\mathbf{2}}$ and 3,3'-dimethyl-4,4'-bipyridinium unit, i.e. $\mathbf{V}_{\mathbf{2}}{ }^{\mathbf{2}}$. The rigid spacer $\mathbf{S}$ consists of three $p$ phenylene units, and the $\pi$-electron-donating ring is bis- $p$-phenylene[34]crown-10. The $\mathbf{V}_{\mathbf{1}}$ unit is a stronger electron-acceptor station than $\mathbf{V}_{\mathbf{2}}$, therefore the ring encircles $\mathbf{V}_{\mathbf{1}}$ unit, and it is the stable translational isomer of $\mathbf{1}$ in the ground state. ${ }^{61}$ 

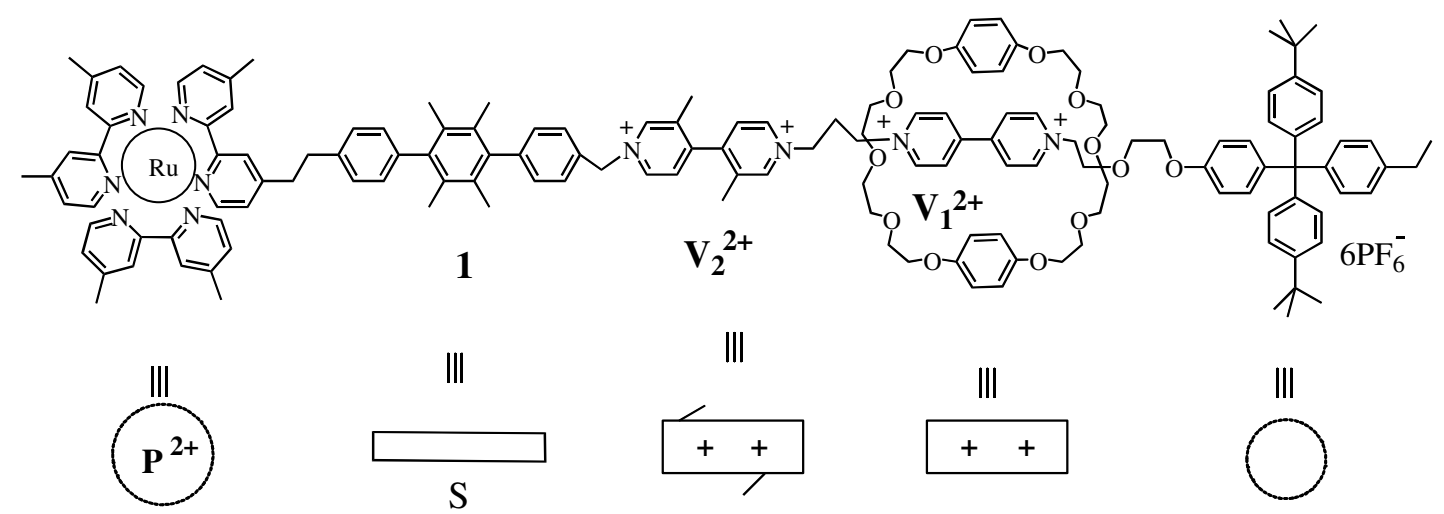

||
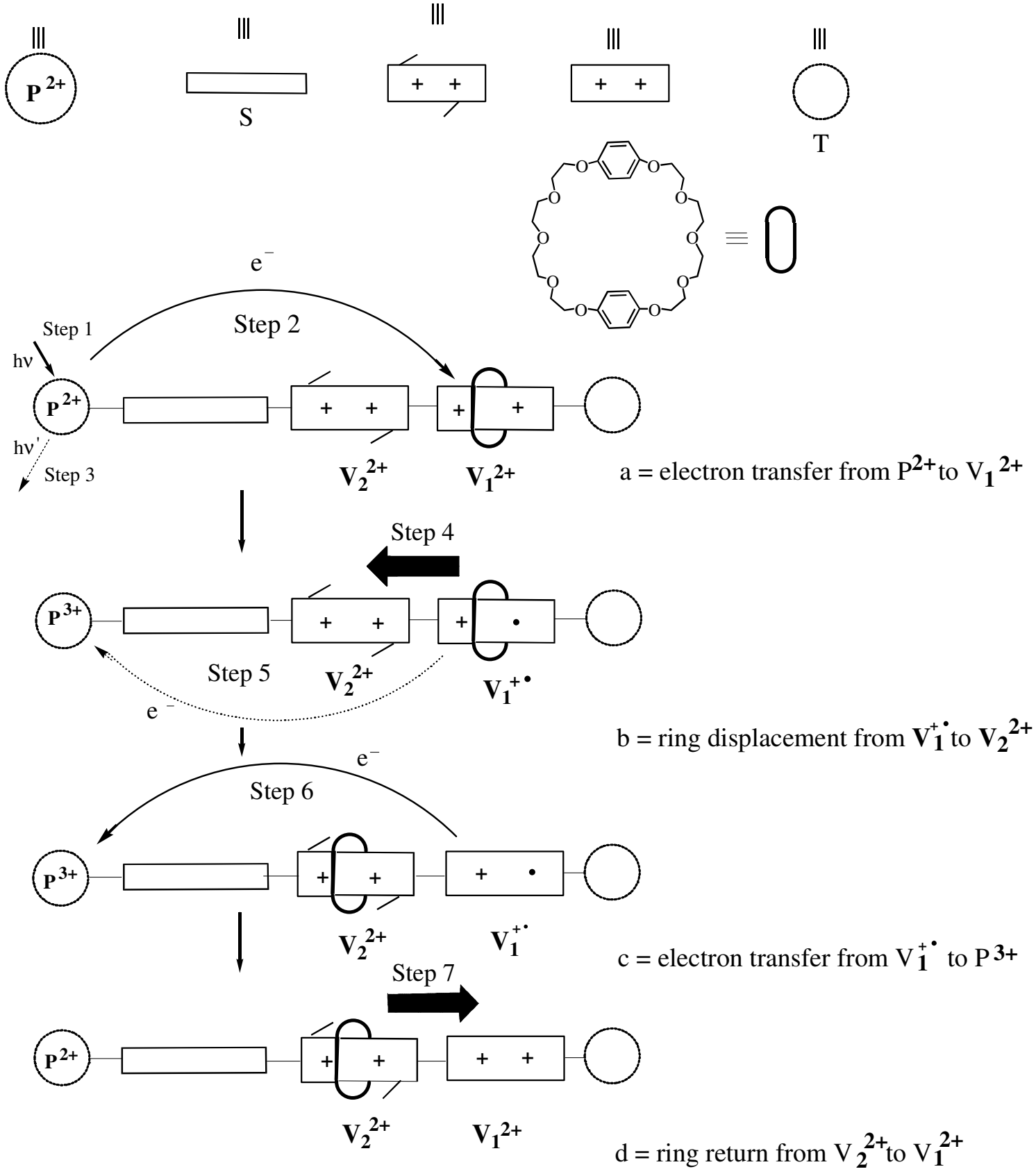

Scheme 1 
The working mechanism of rotaxane 1 involves the "four-stroke" (a-d) molecular shuttle driven by visible light. Excitation of $\mathbf{P}^{2+}$ by light (step 1) results in the electron transfer from $\mathbf{P}^{2+}$ to $\mathbf{V}_{\mathbf{1}}{ }^{\mathbf{2}}$ (step 2), this process competes with the intrinsic decay of the $\mathbf{P}^{\mathbf{2 +}}$ excited state (step 3 ). Upon reduction of $\mathbf{V}_{\mathbf{1}}{ }^{2+}$, deactivating $\mathbf{V}_{\mathbf{1}}{ }^{2+}$ by formation of $\mathbf{V}_{\mathbf{1}}{ }^{+\bullet}$, the ring moves to $\mathbf{V}_{\mathbf{2}}{ }^{2+}$ (step 4), this step competes with the back electron transfer from $\mathbf{V}_{\mathbf{1}}^{+\bullet}$ to the oxidized unit $\mathbf{P}^{\mathbf{3 +}}$ (step 5).

The back electron transfer from the reduced station $\mathbf{V}_{\mathbf{1}}^{+\bullet}$ to the oxidized unit $\mathbf{P}^{\mathbf{3 +}}$ (step 6) restores the electron-acceptor ability of $\mathbf{V}_{\mathbf{1}}{ }^{+\bullet}$ by formation of $\mathbf{V}_{\mathbf{1}}{ }^{2+}$. As a result, a back movement of the ring from $\mathbf{V}_{\mathbf{2}}{ }^{2+}$ occurs (step 7). The above forward and backward movement of the ring presents a full "four-stroke" mechanical cycle (Scheme 1).

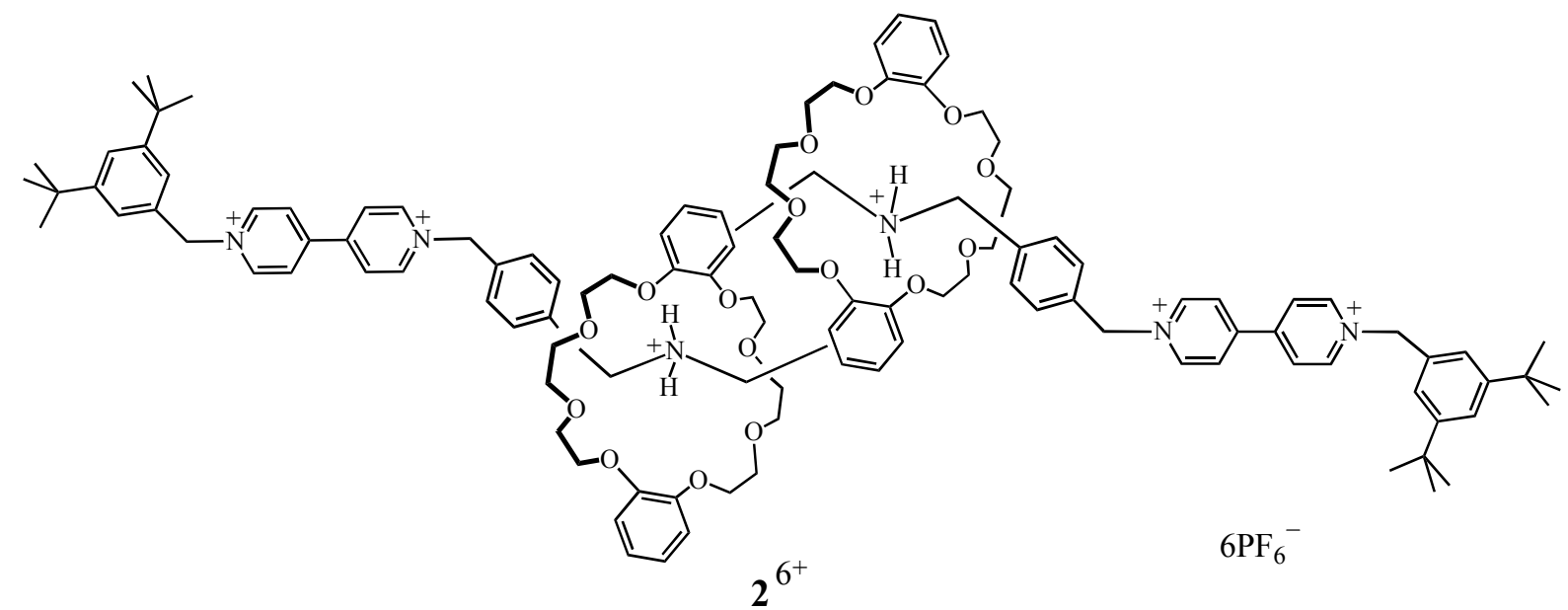

expanded system $\mathbf{A}$
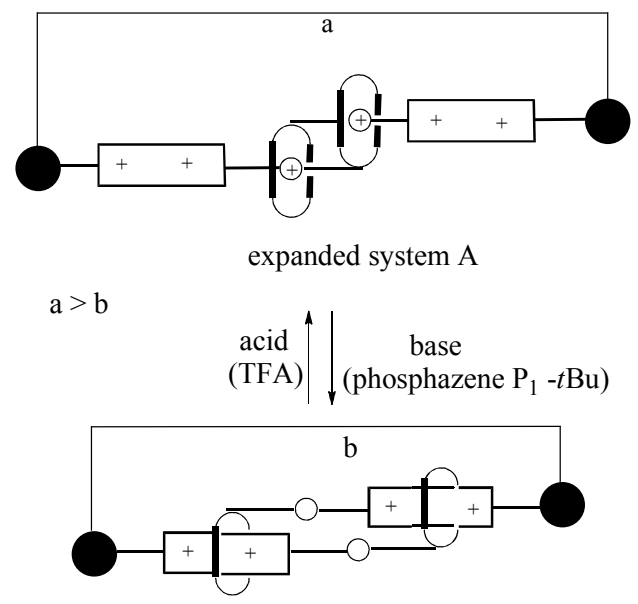

contracted system B

\section{Scheme 2}

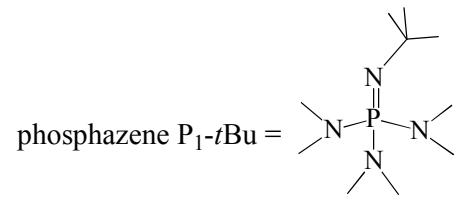


The quantitative comparison of calculations with experimental findings can be achieved by calculating the MM (molecular mechanical) free-energy profile and then the shuttling relaxation time by solving the Fokker-Planck equation.

The role of counterions is very important and should be taken into account for the computational reproduction of the observed shuttling kinetics. Anions are strongly bound to the thread, it was shown that the shuttling is almost barrierless in the absence of counterions. If the interaction between the positively charged rotaxane and its counteranions could be weakened, either by changing the counterion or by changing the solvent, such system would be able to work as a fast-switching molecular machine.

Another structure interesting in building molecular machines is the bistable system $\mathbf{2}^{\mathbf{6 +}}$ based on a two-component [c2]daisy chain stoppered at both ends. Each component consists of the crown ether ring bound with the thread containing two stations, i.e. viologen and $\mathrm{NH}_{2}^{+}$units (Scheme 2). ${ }^{62}$

In this system, in $\mathrm{CD}_{3} \mathrm{CN}$ solution the two crown ether rings move between two recognition sites under acid-base control; during this process the length of the whole system (i.e. the distance between two stoppers) undergoes contraction by treatment with a base $(A \rightarrow B)$ and expansion by treatment with acid $(B \rightarrow A)$. Such behavior is similar to the action of a muscle.

In $\mathrm{A}$ the rings encircle the $-\mathrm{NH}_{2}{ }^{+}$- units; the rings are close by, i.e. the system is expanded, the distance between two stoppers is a. Upon addition of phosphazene $\mathrm{P}_{1}$ - $t \mathrm{Bu}$ base the $-\mathrm{NH}_{2}{ }^{+}$- units undergo deprotonation, resulting in shift of both rings to viologen units, this motion leads to formation of $\mathrm{B}$, where rings are far away from each other, i.e. the system is contracted, the distance between two stoppers is $b$. Since $a>b$, the system behaves as a muscle. The addition of trifluoroacetic acid causes the reprotonation of -NH- groups to- $\mathrm{NH}_{2}{ }^{+}$- and return to original expanded system A. The above reversible muscle-like structures are promising for design of molecular machines.

In daisy chains the molecules are linked together by mechanical bonds; the mechanically interlocked molecules (MIMs) attract today a growing attention. ${ }^{10,63}$ One should point out that the polymers in which repeating units are connected by mechanical bond, i.e. mechanically interlocked polymers are promising for use in nanotechnology and material science. ${ }^{64-70}$

Below the synthesis of polymer daisy chain 3 using "threading-followed-by-polymerization" method is described. ${ }^{71}$ It is noteworthy that in this procedure the tedious syntheses of monomers are avoided. The synthesis begins with the treatment of acid $\mathbf{4}$ containing crown ether unit with thionyl chloride affording acid chloride $\mathbf{5}$ which directly, without purification was mixed with viologen derivative 6 in acetone at $-70{ }^{\circ} \mathrm{C}$, this low temperature was employed to minimize the esterification and maximize the complexation of $\mathbf{6}$ with $\mathbf{5}$ affording the pseudorotaxane-type monomer $\mathbf{6 \cdot 5}$. The temperature was allowed next to rise slowly to $-50{ }^{\circ} \mathrm{C}$ and triethylamine was added to catalyze esterification, then the reaction mixture was warmed to room temperature.

The in situ generated $\mathbf{6 \cdot 5}$ underwent polymerization to give the polymer daisy chain $\mathbf{3}$. After the exchange of $\mathrm{Cl}^{-}$into $\mathrm{PF}_{6}^{-}$ions, the side products were removed by precipitation with DMSO. 


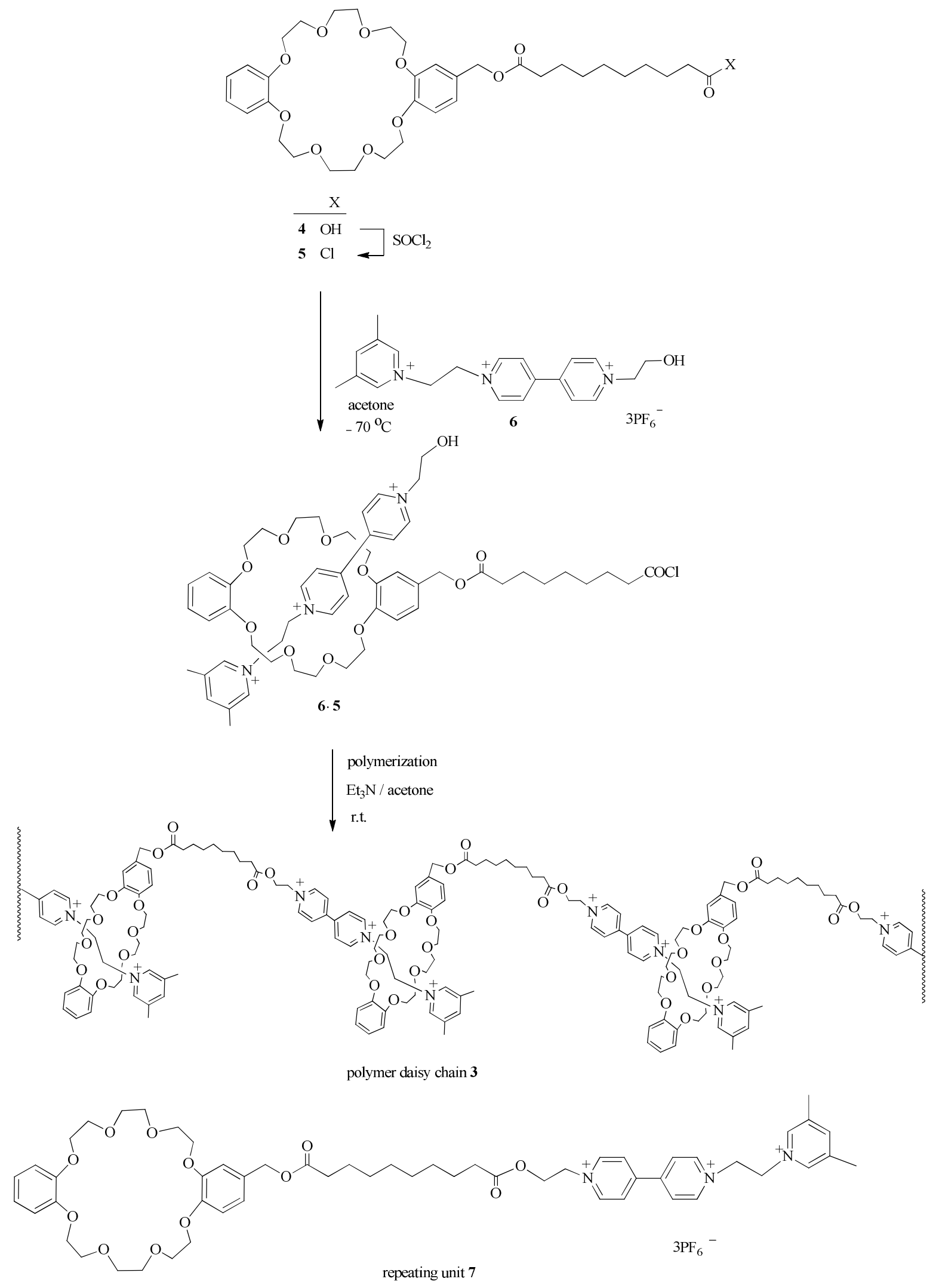

Scheme 3 
It was established that 45 repeating units 7 exist in a single polymer chain of $\mathbf{3}$, the molecular weight of 3 is $64 \mathrm{kDa}^{72}$

The above results show that the dynamic supramolecular monomers, i.e. monomers with different parts linked by noncovalent bonds may serve for convenient construction of mechanically interlocked polymers (Scheme 3).

In order to perform a quantitative conformational study of redox-active [2] rotaxanes, at first the conformational analysis of [2] rotaxane $\mathbf{8}^{\mathbf{2 +}}$ serving as a model and of its radical cation $\mathbf{8}^{+\bullet}$ was made. Rotaxane $\mathbf{8}^{\mathbf{2 +}}$ consists of the viologen $\mathbf{V}^{\mathbf{2 +}}$, the ring $\mathbf{9}$ and stoppers $\mathbf{A}$ and $\mathbf{B}$. The stopper $\mathbf{A}$ is rigidly connected with viologen, while the stopper $\mathbf{B}$ ia attached to viologen by a flexible polyether chain. In this investigation the combined electrochemical techniques and NMR spectroscopic methods such as COSY, NOESY and PASSY (paramagnetic line-broadening and suppression) were used (Scheme 4).

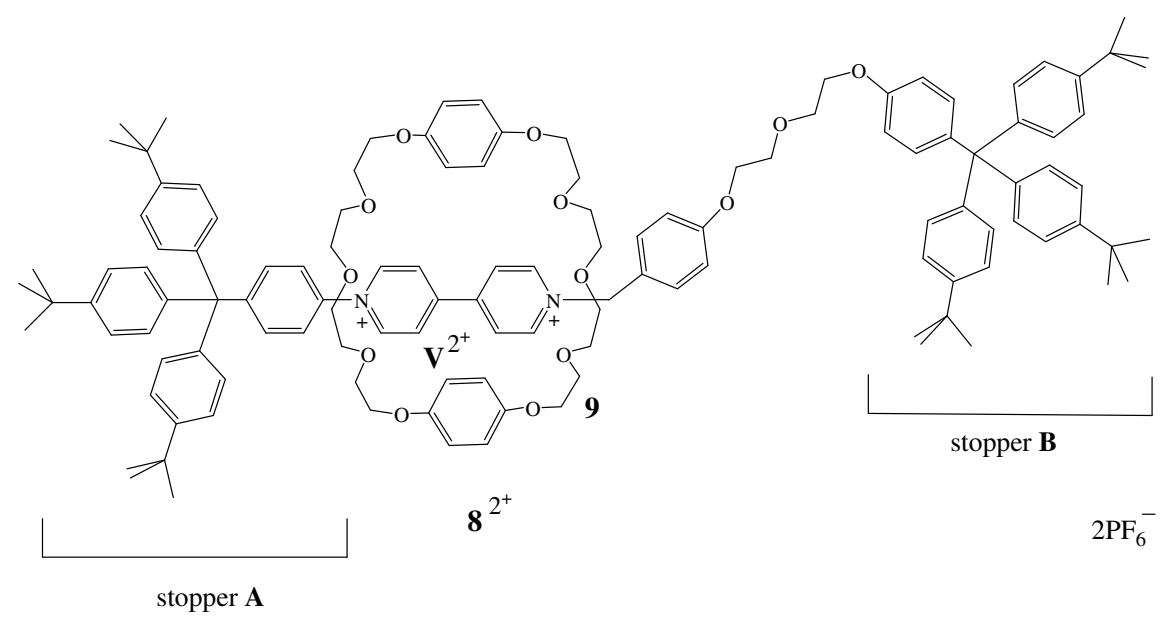

\section{Scheme 4}

It was observed that in the rotaxane $\mathbf{8}^{\mathbf{2 +}}$ in its dicationic $\mathbf{V}^{\mathbf{2 +}}$ state in solution the thread is folded, the $\mathbf{B}$ stopper being directed back to the centre of the molecule, the crown ether 9 encircles the viologen site. Upon one-electron reduction of viologen, affording the radical cation $\mathbf{V}^{+\bullet}$, the thread retains its folded conformation and $\mathbf{9}$ remains localized at the $\mathbf{V}^{\mathbf{+}^{\bullet}}$, although $\mathbf{V}^{\mathbf{+}^{\bullet}}$ has lower affinity than $\mathbf{V}^{2+}$ for $\mathbf{9}$. It was found that even in the case of the fully reduced viologen $\mathbf{V}^{\mathbf{0}}$, the ring $\mathbf{9}$ still resides at the viologen unit. ${ }^{73}$

The above study of the simple [2] rotaxane $\mathbf{8}$ i.e. containing one viologen unit was followed by conformational study in solution of two bistable rotaxanes $\mathbf{1 0}$ and $\mathbf{1 1}$, i.e. containing two viologen units. ${ }^{74}$ The investigation of both rotaxanes $\mathbf{1 0}$ and $\mathbf{1 1}$ in their parent and reduced states was made using the same electrochemical and NMR spectroscopic methods as in the former experiment. $^{73}$ 
Rotaxanes 10 and 11 have been synthesized, they both have two stations, $\mathbf{V}_{\mathbf{1}}$ and $\mathbf{V}_{\mathbf{2}}$, the links $\mathbf{L}_{\mathbf{1}}$ and $\mathbf{L}_{\mathbf{2}}$ (in $\mathbf{1 0}$ and $\mathbf{1 1}$, respectively) between two recognition sites, and stoppers $\mathbf{A}$ and $\mathbf{B}$; the crown ether 9 is a ring.
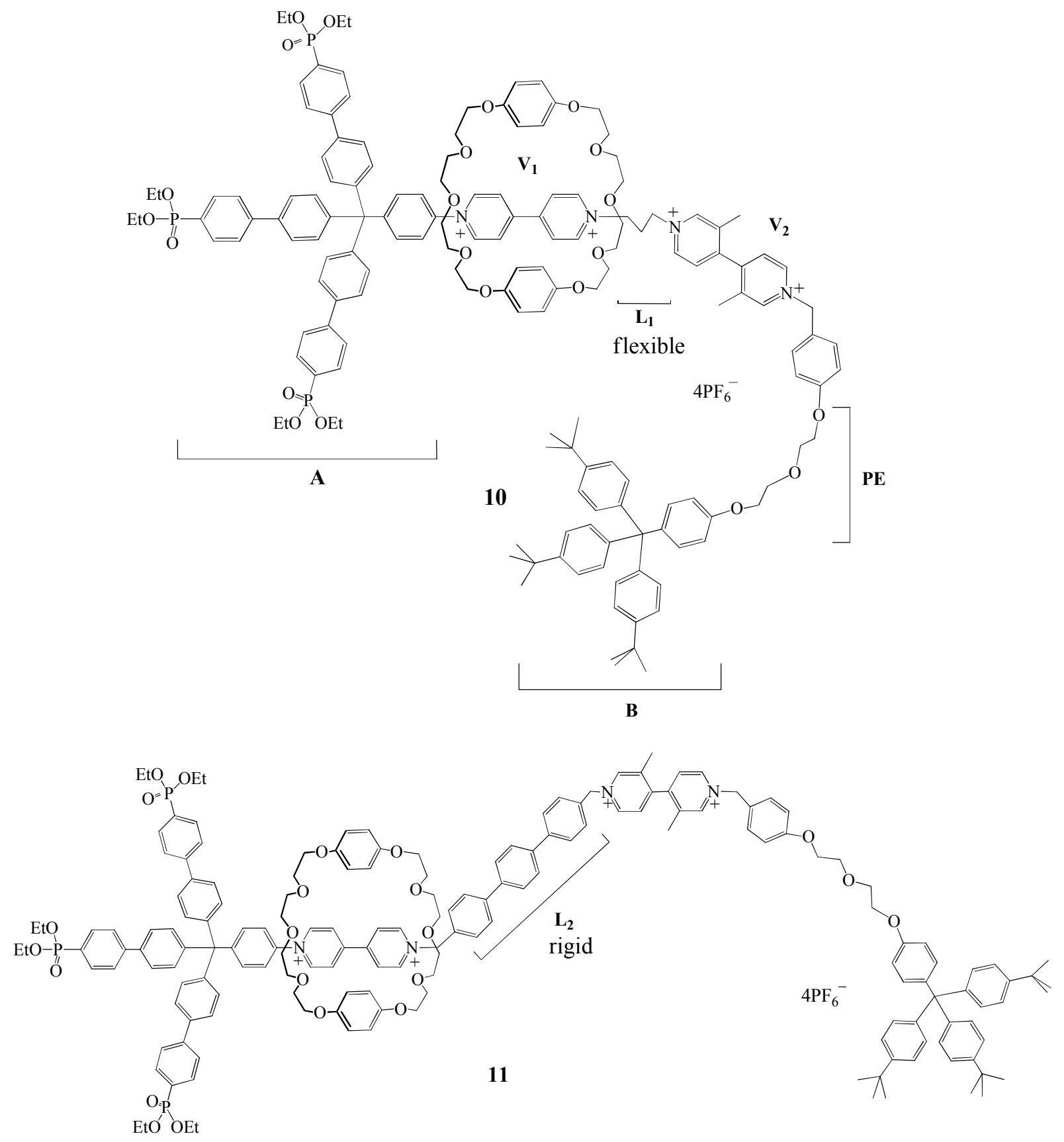

\section{Scheme 5}

Tripodal stopper A serves in rotaxanes $\mathbf{1 0}$ and $\mathbf{1 1}$ for attachment of the thread to the surface of semiconductors or metals; in experiments the attachment to the surface of $\mathrm{TiO}_{2}$ nanoparticles 
and nanostructured electrodes was made. Both rotaxanes 10 and 11 contain flexible polyether PE units connecting $\mathbf{V}_{\mathbf{2}}$ with the stopper $\mathbf{B}$ while their links between stations $\mathbf{V}_{\mathbf{1}}$ and $\mathbf{V}_{\mathbf{2}}$ have different rigidity. In rotaxane $\mathbf{1 0}$ the viologen units $\mathbf{V}_{\mathbf{1}}$ and $\mathbf{V}_{\mathbf{2}}$ are bound by a flexible trimethylene chain $\mathbf{L}_{\mathbf{1}}$, while in rotaxane $\mathbf{1 1}$ the viologen units $\mathbf{V}_{\mathbf{1}}$ and $\mathbf{V}_{\mathbf{2}}$ are linked by a rigid terphenylene chain $\mathbf{L}_{2}$ (Scheme 5). ${ }^{74}$

It should be pointed out that the flexibility of the chains $\mathbf{L}_{\mathbf{1}}$ and $\mathbf{L}_{\mathbf{2}}$ influences the shuttling of the ring. In $\mathbf{1 0}$ the trimethylene link $\mathbf{L}_{\mathbf{1}}$ is flexible and may be folded, therefore the shuttling of the ring is limited, while in $\mathbf{1 1}$ the terphenylene link $\mathbf{L}_{\mathbf{2}}$ is rigid and the shuttling proceeds without limitations. In the study the role of intramolecular folding in the shuttling of the ring 9 in rotaxanes $\mathbf{1 0}$ and $\mathbf{1 1}$ was examined.

In 10 and 11, in the parent state the ring resides at $\mathbf{V}_{\mathbf{1}}$, since $\mathbf{V}_{\mathbf{1}}$ is more electron deficient and less sterically hindered than $\mathbf{V}_{\mathbf{2}}$. At the beginning the behavior of $\mathbf{1 0}$ and $\mathbf{1 1}$ was investigated when $\mathbf{V}_{\mathbf{1}}$ was reduced to the first reduced state. It was possible to selectively reduce $\mathbf{V}_{\mathbf{1}}$ (without the reduction of $\mathbf{V}_{\mathbf{2}}$ ), since $\mathbf{V}_{\mathbf{1}}$ and $\mathbf{V}_{\mathbf{2}}$ have sufficiently different reduction potentials. The reduction of $V_{\mathbf{1}}$ in $\mathbf{1 0}$ and $\mathbf{1 1}$ may be performed by applying an appropriate negative potential or by using $\mathrm{Zn}$ metal, under these conditions the stations $\mathbf{V}_{2}$ do not undergo reduction; as a result $\mathbf{1 0} \cdot 3 \mathrm{PF}_{6}$ and $\mathbf{1 1} \cdot 3 \mathrm{PF}_{6}$ in singly reduced radical cation states are formed.

The given above NMR methods enable the monitoring of structural and conformational changes of [2]rotaxane molecule at different oxidation states. It was found that in radical cations of reduced viologens the unpaired electron density causes a measurable PRE (paramagnetic relaxation enhancement). The PRE values allow to characterize the localization of the ring and to estimate the conformation of the thread of the [2]rotaxane in the reduced states.

In $10 \cdot 3 \mathrm{PF}_{6}$ the viologen $\mathbf{V}_{2}$ is folded back toward $\mathbf{V}_{\mathbf{1}}$, so that methyl groups of $\mathbf{V}_{\mathbf{2}}$ can approach $\mathbf{V}_{\mathbf{1}}$. The analysis of PRE has shown that the stopper $\mathbf{B}$ starts to be in the vicinity of $\mathbf{V}_{\mathbf{1}}$ due to the folding of $\mathbf{L}_{1}$ and of the $\mathbf{P E}$ chain. In $\mathbf{1 0} \cdot 3 \mathrm{PF}_{6}$ the ring still predominantly resides at $\mathbf{V}_{\mathbf{1}}^{+\bullet}$, although the interaction of the ring with $\mathbf{V}_{\mathbf{1}}^{+\bullet}$ is weakened since $\mathbf{V}_{\mathbf{1}}^{+\bullet}$ has higher electron density than had $\mathbf{V}_{\mathbf{1}}{ }^{2+}$. Even after a second reduction (i.e. for $\mathbf{1 0} \cdot 2 \mathrm{PF}_{6}$ ) the ring still encircles $\mathbf{V}_{\mathbf{1}}$. At last, after the third reduction (i.e. for $\mathbf{1 0} \cdot \mathrm{PF}_{6}$ ), the ring shuttles to $\mathbf{V}_{\mathbf{2}}$

In $11 \cdot 3 \mathrm{PF}_{6}$ however, $\mathbf{V}_{2}$ cannot approach to $\mathbf{V}_{1}$; the ring mainly resides at $\mathbf{V}_{2}$ which is a weaker recognition site than $\mathbf{V}_{\mathbf{1}}$. The folding of $\mathbf{L}_{\mathbf{2}}$ in $\mathbf{1 1}$ is impossible in all reduction states. The shuttling occurs after the first reduction (i.e. for $\mathbf{1 1} \cdot 3 \mathrm{PF}_{6}$ ), in this time the ring encircles $\mathbf{V}_{\mathbf{2}}$, which is a weaker recognition site than $\mathbf{V}_{\mathbf{1}}$, and also after the second reduction (i.e. for $11 \cdot 2 \mathrm{PF}_{6}$ ) and after the third reduction (i.e. for $\mathbf{1 1} \cdot \mathrm{PF}_{6}$ ) the ring always encircles $\mathbf{V}_{\mathbf{2}}$

The above investigation of tripodal rotaxanes $\mathbf{1 0}$ and $\mathbf{1 1}$ shows that the nature of the link $\mathbf{L}$ between stations $\mathbf{V}_{\mathbf{1}}$ and $\mathbf{V}_{\mathbf{2}}$ is crucial for their switching ability. ${ }^{74}$

In order to explain how electrostatic attraction may help to control the shuttling process, [2]rotaxanes and related [2]pseudorotaxanes containing oppositely charged threads and rings have been investigated. ${ }^{75}$ In these systems, referred to as ion-paired [2]rotaxanes and ion-paired [2]pseudorotaxanes, the positive and negative charges are compensated and the mutual molecular recognition is considerably increased by electrostatic attraction between components, which are 
not only mechanically interlocked, but also strongly electrostatically attached. The studied rotaxanes and pseudorotaxanes contain doubly positively charged viologen threads which go through doubly negatively charged crown ether rings.

As examples served the ion-paired [2] rotaxanes and ion-paired [2]pseudorotaxanes consisting of the thread incorporating cationic viologen unit and of bis- $p$-phenylene-34-crown-10 rings with anionic groups $-\mathrm{COO}^{-}$and $-\mathrm{SO}_{3}^{-}, 12$ and 13 , respectively, the neutral crown ethers 9 and 14 served for comparison purposes. It was observed that the association constants of viologens 15 and 16 with anionic crown ethers 12 and 13 are higher than those with neutral crown ethers 9 and 14; the affinity of the investigated crown ethers toward viologens decreases in the order: $\mathbf{1 3}>\mathbf{1 2} \geq \mathbf{1 4}>\mathbf{9}$ (Scheme 6$)^{75}$
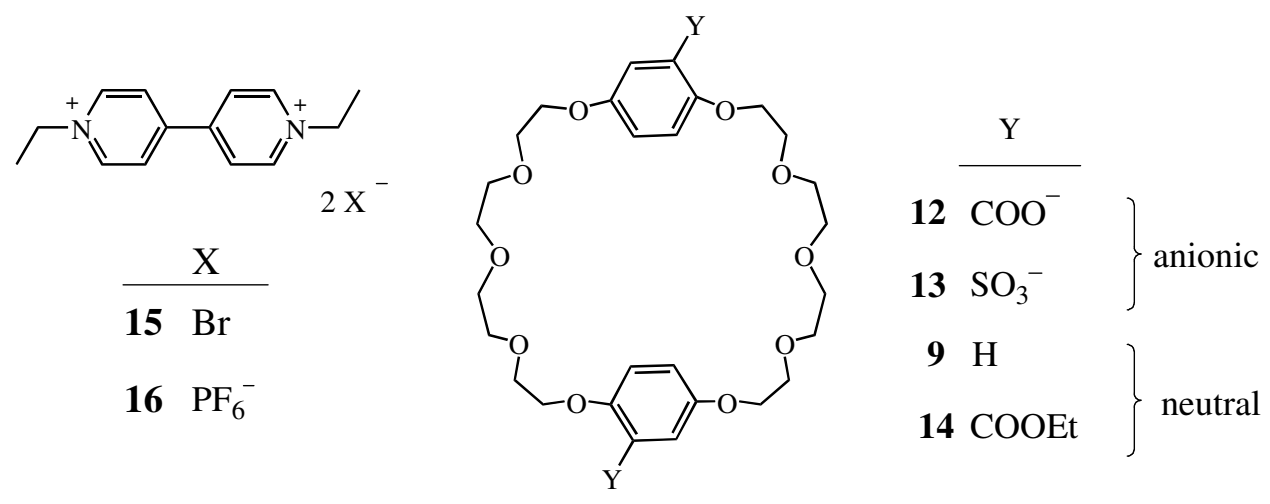

\section{Scheme 6}

Synthesis of ion-paired [2]rotaxanes was made using the reaction of monocation precursor 17 with the crown ether 18 and the stopper component 19, the formed [2]rotaxane 20 was converted by sodium bicarbonate into ion-paired [2] rotaxane 21 (Scheme 7). 

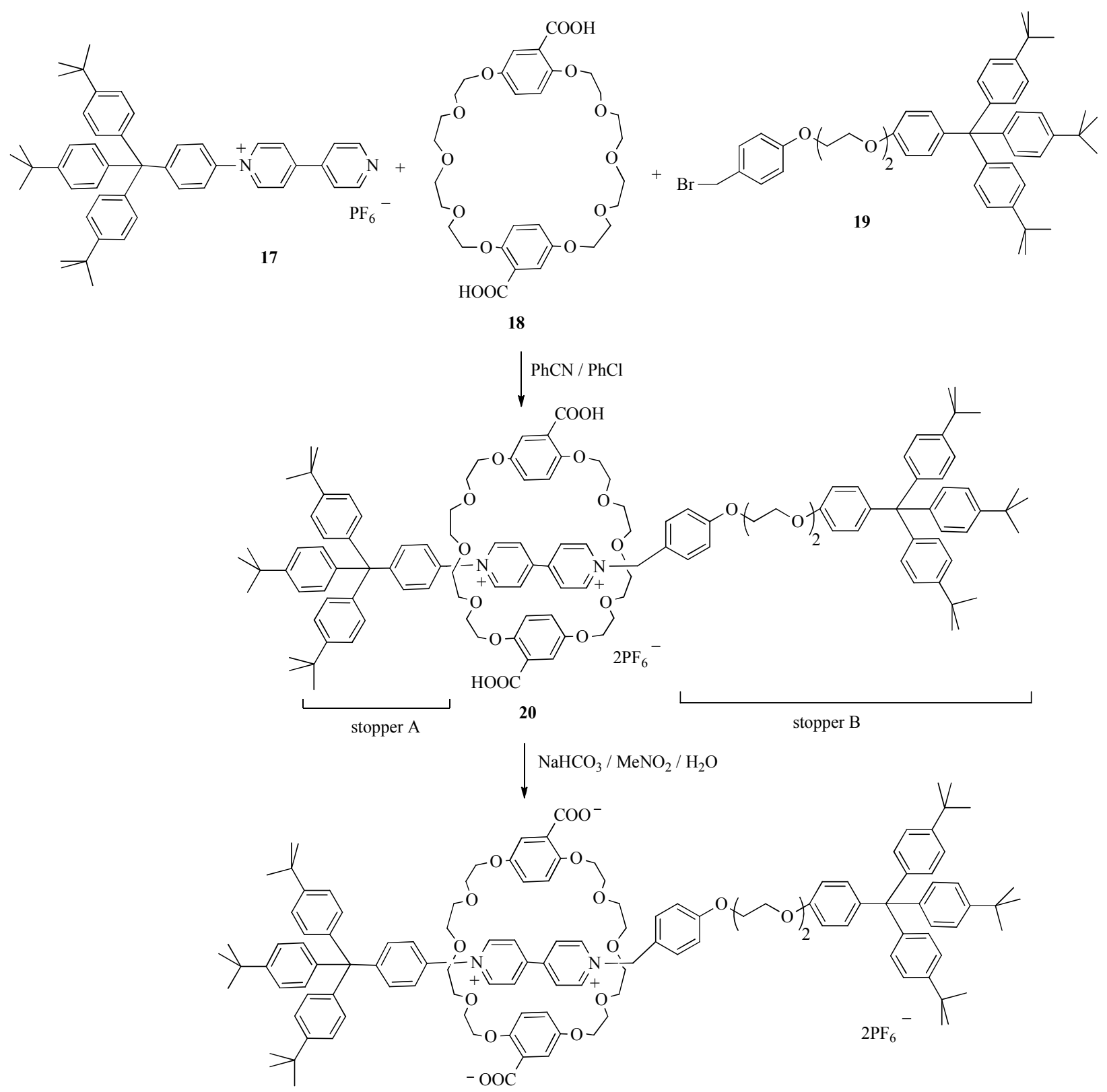

\section{Scheme 7}

It was found that the reaction of $\mathbf{1 7}$ with the mixture of syn-and anti-isomers of the crown ether 13 (in form of the $\mathrm{Bu}_{4} \mathrm{~N}^{+}$salt) and with 19 affords in $50 \%$, two syn- and anti-isomers of ion-paired rotaxanes 22 and 23,respectively, due to the presence of equal amounts of syn- and anti- isomers in the starting material 13. One should point out that, contrary to the starting $\mathbf{1 3}$, the isomers 22 and $\mathbf{2 3}$ could be separated; it was observed that the anti- rotaxane $\mathbf{2 3}$ shows cycloenantiomerism (Scheme 8). 


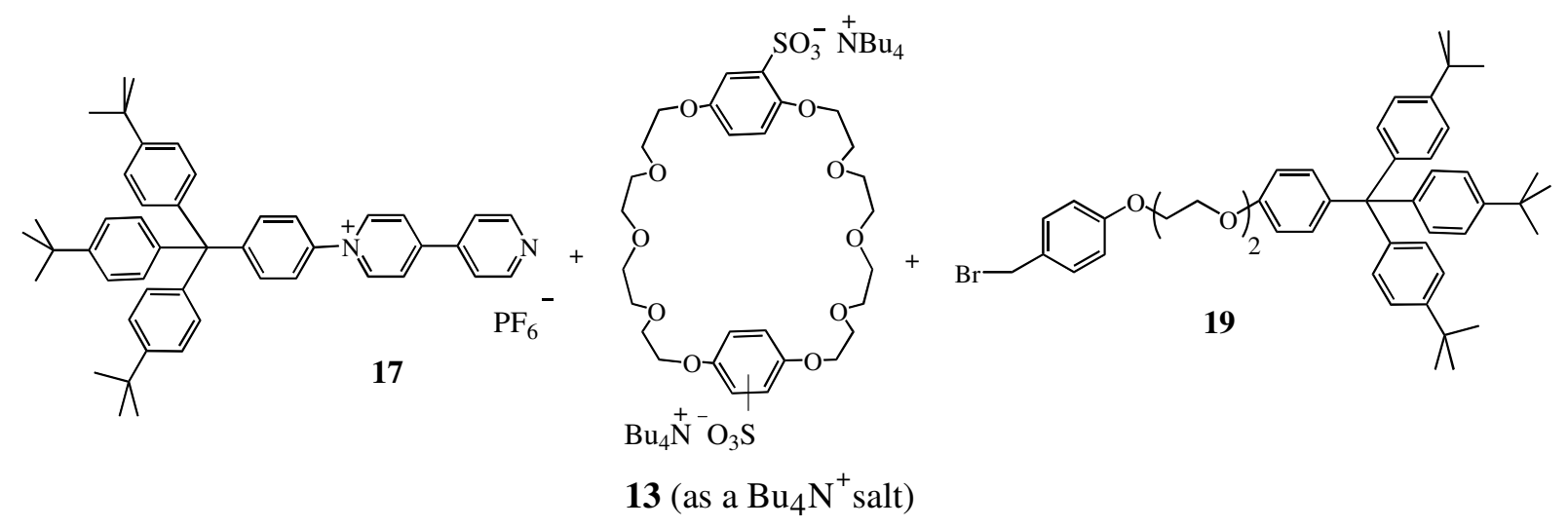

(mixture of syn- and anti-isomers)

$-\mathrm{Bu}_{4} \mathrm{~N}^{+} \mathrm{PF}_{6}^{-} \downarrow \mathrm{PhCN}$

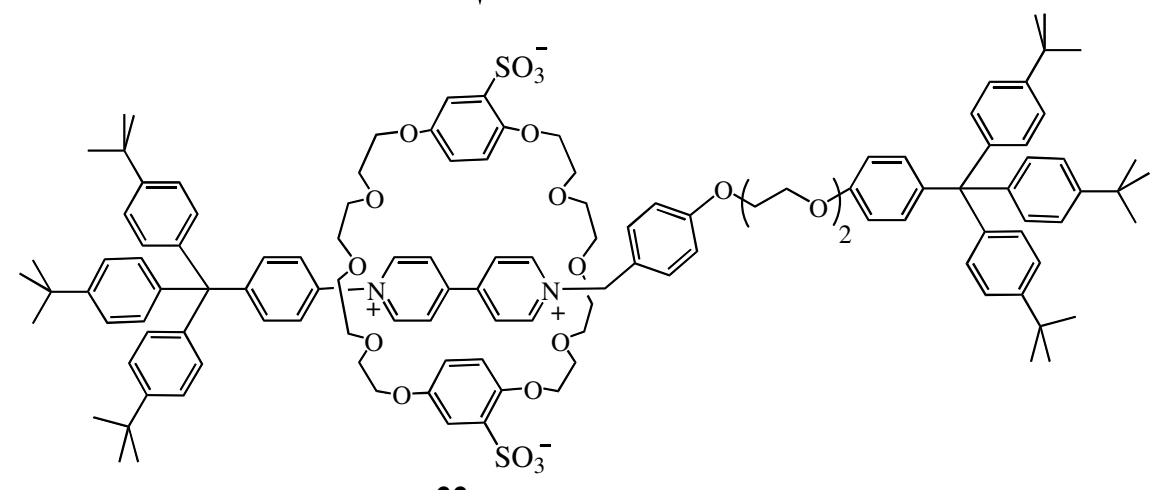

22

syn

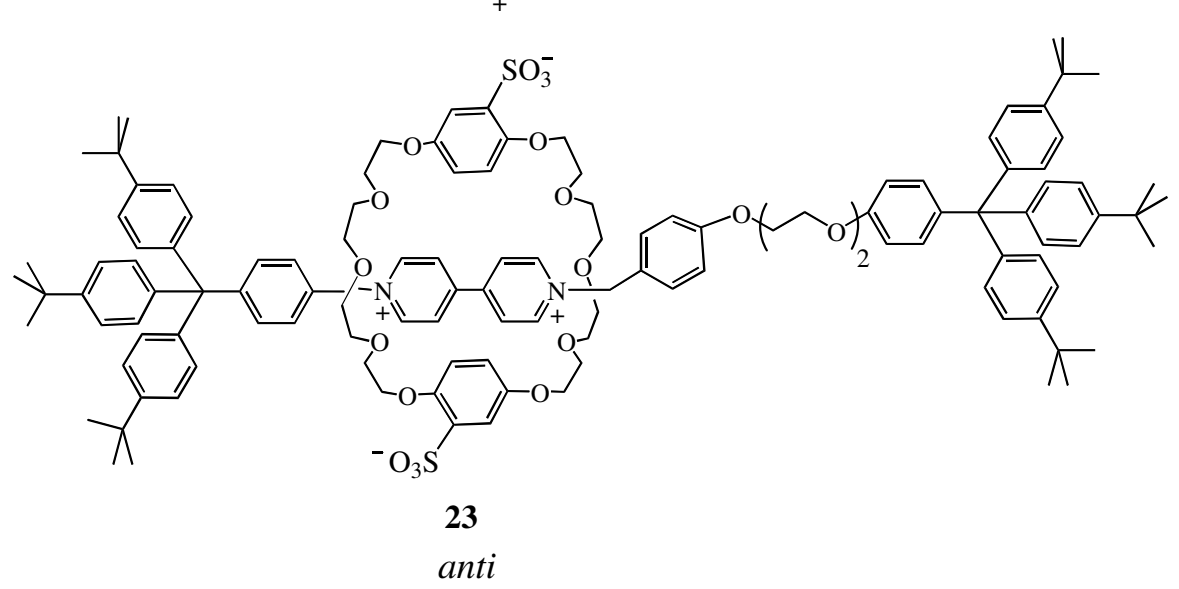

\section{Scheme 8}

Synthesis of ion-paired [2]pseudorotaxanes involves the reaction of viologen 16 with crown ethers 12 and 13 (in form of $\mathrm{Me}_{4} \mathrm{~N}^{+}$and $\mathrm{Bu}_{4} \mathrm{~N}^{+}$salts, respectively) in aqueous ethanol affording 
[2]pseudorotaxanes $\mathbf{2 4}$ and $\mathbf{2 5}$. One should note that $\mathbf{2 4}$ and $\mathbf{2 5}$ are considerably stable, they exist in solution and in the solid state (Scheme 9).

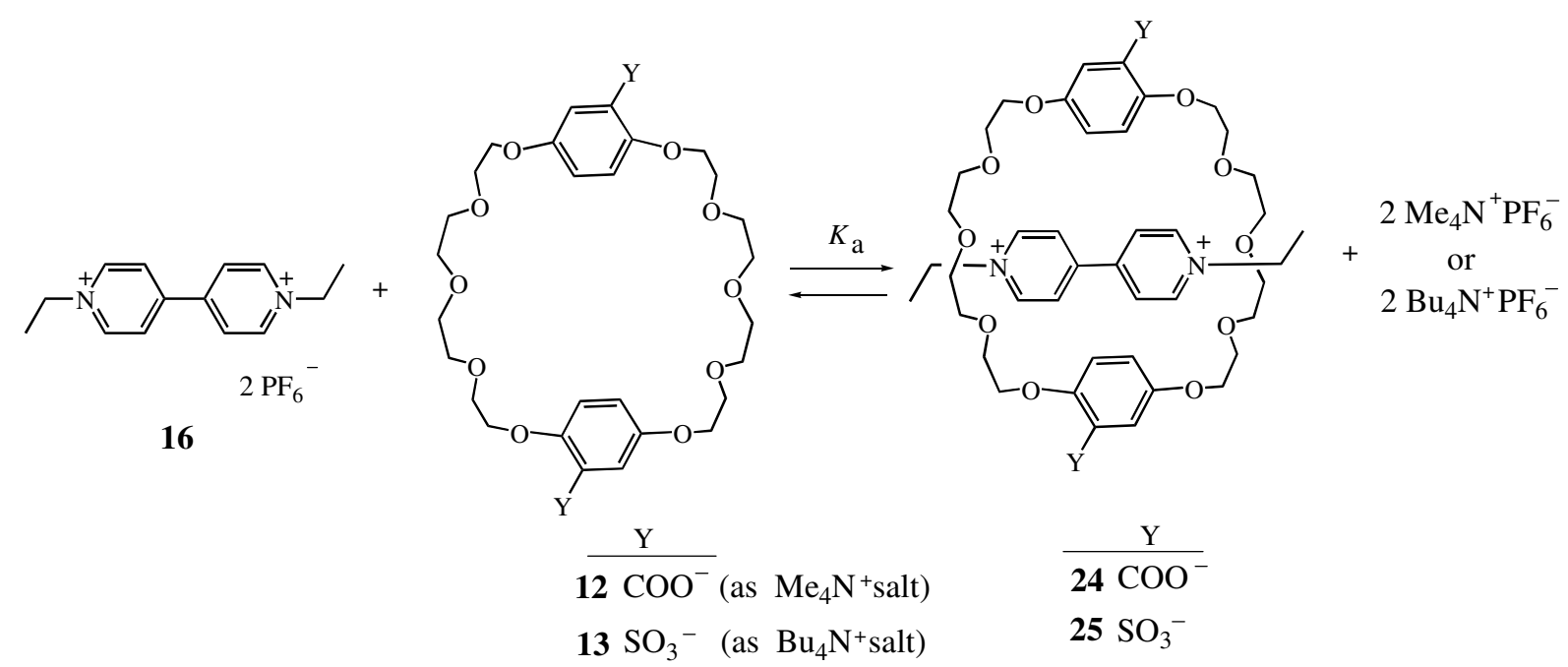

\section{Scheme 9}

The crystal structures of hydrated pseudorotaxanes $\mathbf{2 4}$ and $\mathbf{2 5}$ have been examined:

In pseudorotaxane $\mathbf{2 4}$, the viologen cationic nitrogen atoms and the anionic carboxylate groups of the ring $\mathbf{1 2}$ are far from each other, and the carboxylates point away from the viologen unit into layers of hydrating water molecules. The hydration shell of water molecules (twelve water molecules per each ion-paired [2] rotaxane molecule) forms layers separating adjacent ion-paired [2]pseudorotaxane units. Such hydration prevents the direct contacts of positively charged nitrogen atoms with carboxylate groups.

In pseudorotaxane 25, however, the viologen cationic nitrogen atoms are more close to anionic sulfonate groups of the ring 13 than in the case of 24. Moreover, the number of hydrating water molecules is lower than for $\mathbf{2 4}$ (it is only two per each ion-paired [2]pseudorotaxane molecule), and as a result, in the solid $\mathbf{2 5}$ the viologen cationic nitrogen atoms and anionic sulfonate groups are not separated from each other by layers of water molecules, therefore $K_{\mathrm{a}}$ of $\mathbf{2 5}$ is higher than $K_{\mathrm{a}}$ of $\mathbf{2 4}$. The above observations show that the sulfonate groups provide a better charge delocalization than the carboxylate groups, and enhance the stability of ion-paired [2]pseudorotaxane.

One should point out that the behavior of ion-paired [2] rotaxanes and ion-paired [2]pseudorotaxanes is different from common [2]rotaxanes and [2]pseudorotaxanes since in the ion-paired systems the electrostatic attraction between components exists. It is noteworthy that carboxylate groups of ion-paired [2] rotaxanes can be reversibly protonated, in the contrary to sulfonate groups which cannot be protonated, due to this property rotaxanes containing sulfonated rings can maintain their charges in media of a wider acidity range. One should also note that ion-paired [2]pseudorotaxanes are considerably stable even in aqueous solutions. 
The above described ion-paired [2]rotaxanes and ion-paired [2]pseudorotaxanes, consisting of oppositely charged interlocked components are promising for design of molecular electronic devices driven by electrostatic attraction forces. ${ }^{75}$

\subsection{Pseudorotaxanes}

Pseudorotaxanes are building blocks for interlocked supramolecular systems; due to their interesting properties they are widely investigated. Below selected examples of pseudorotaxanes with threads containing viologen units are presented.

Pseudorotaxanes consisting of the thread containing viologen and a terpyridine group with its transition metal complexes and of rings 24-crown-8(A), dibenzo-24-crown-8(B) or dinaphtho24-crown-8(N) were studied in view of their ON/OFF behavior (Scheme 10). ${ }^{76}$

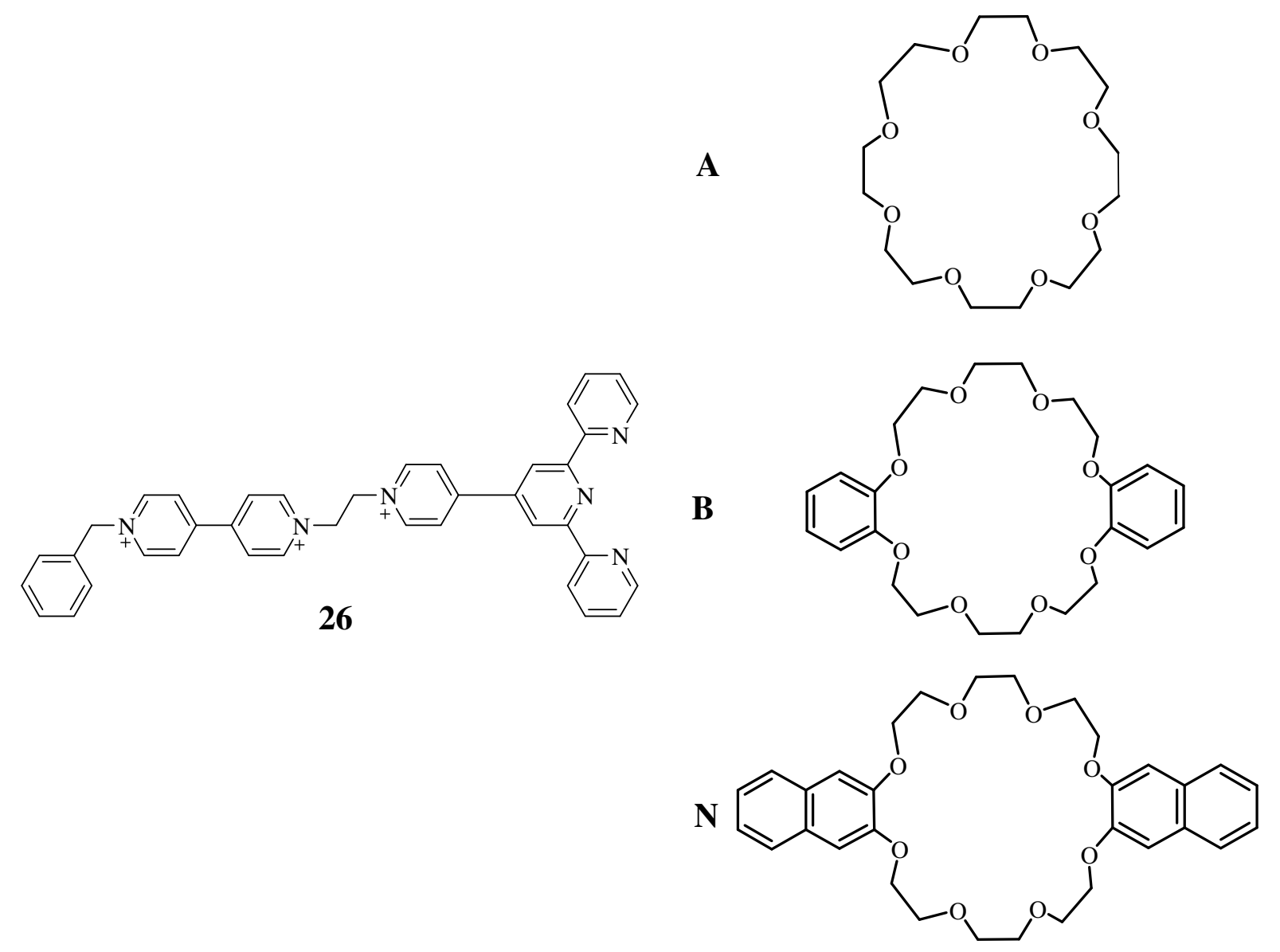

\section{Scheme 10}

First, the association of the thread $\mathbf{2 6}^{\mathbf{3 +}}$ containing the square planar complex $[\operatorname{PtMe}(\mathbf{2 6})]^{4+}$ and the octahedral complex $\left[\operatorname{Ru}(\text { terpy)(26) }]^{5+}\right.$ with crown ethers $\mathbf{A}, \mathbf{B}$ and $\mathbf{N}$ yielding pseudorotaxanes was made. The $\mathrm{Pt}(\mathrm{II})$ and $\mathrm{Ru}(\mathrm{II})$ ions were selected since they afford robust, inert complexes with terpyridine ligand. The results of experiments show that the $K_{\mathrm{a}}$ values for 
[2]pseudorotaxanes containing rings $\mathbf{A}$ and $\mathbf{B}$ increase with higher $\pi$-stacking in order $\mathbf{A}<\mathbf{B}$, and no significant difference exists in the association between free $\mathbf{2 6}^{\mathbf{3 +}}$, square planar complex or octahedral complex. However, when crown ether $\mathbf{N}$ is used as the ring, the above typical trend exists no more, and the observed differences depend on the coordination geometry of the complex (Scheme 11).

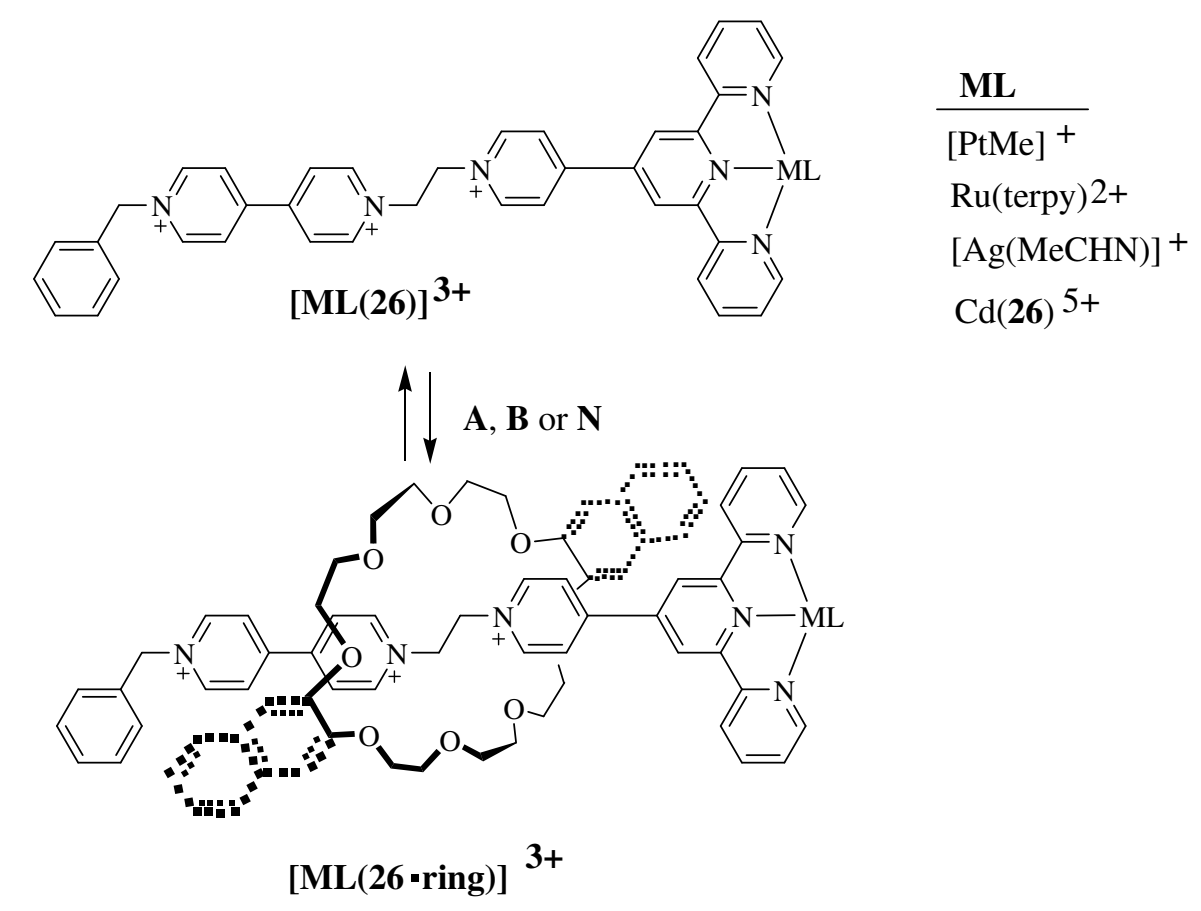

\section{Scheme 11}

As an explanation it was established that in the case of the pseudorotaxane $[\operatorname{PtMe}(\mathbf{2 6} \cdot \mathbf{N})]^{4+}$, i.e. 27, the square planar Pt complex provides a large electron-deficient surface for $\pi$-stacking with the naphtho unit of $\mathbf{N}$, therefore the interaction between thread and ring is enhanced and $K_{\mathrm{a}}$ of pseudorotaxane $\mathbf{2 7}$ is higher than for the pseudorotaxane $[\operatorname{Ru}(\operatorname{terpy})(\mathbf{2 6} \cdot \mathbf{N})]^{5+}$, i.e. 28. This difference results from the fact that the octahedral $\mathrm{Ru}$ complex, present in $\mathbf{2 8}$ creates a steric hindrance between the ancillary terpy ligand and the naphtho unit, the $\pi$-stacking is lower than in 27, therefore the $K_{\mathrm{a}}$ of pseudorotaxane $\mathbf{2 8}$ is lower (Scheme 12).

In order to investigate this behavior with more labile metals, as an analogue of $[\mathrm{PtMe}(\mathbf{2 6})]^{4+}$, the square planar complex $[\mathrm{Ag}(\mathrm{MeCN})(\mathbf{2 6})]^{4+}$ was prepared, and as an analogue of $\left[\mathrm{Ru}(\text { terpy)(26) }]^{5+}\right.$ the bis-ligand octahedral complex $\left[\mathrm{Cd}(\mathbf{2 6})_{2}\right]^{8+}$ was used. It was found that the $K_{\mathrm{a}}$ values for formation of [2]pseudorotaxanes from square planar complexes of $\mathrm{Pt}(\mathrm{II})$ and $\mathrm{Ag}(\mathrm{I})$ with $\mathbf{N}$ (27 and 29), respectively) are higher than in the case of octahedral complexes of $\mathrm{Ru}(\mathrm{II})$ and $\mathrm{Cd}(\mathrm{II}),(\mathbf{2 8}$ and $\mathbf{3 0}$, respectively). 


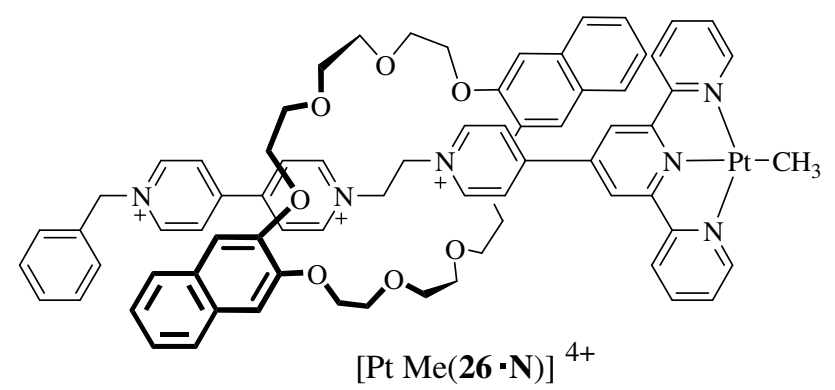

27

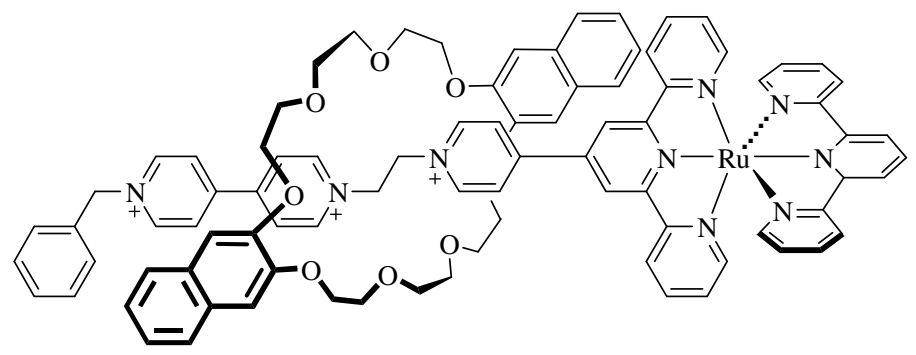

$[\operatorname{Ru}(\text { terpy })(\mathbf{2 6} \cdot \mathbf{N})]^{5+}$

28

\section{Scheme 12}

This observation concerning the influence of coordination environment of the metal on $K_{\mathrm{a}}$ of formed pseudorotaxanes gave an idea for the design of an ON/OFF system in which the conversion between $\mathrm{ON}$ and OFF states occurs by changing one type of metal coordination environment for another ${ }^{77}$ in a similar way as other systems are controlled by $\mathrm{pH}^{78}$ For this purpose the $\mathrm{Ag}(\mathrm{I})$ (square planar) and $\mathrm{Cd}(\mathrm{II})$ (octahedral) complexes were used to construct a system of $\mathrm{OFF} / \mathrm{ON}$ switching by exchanging metal ions, i.e. by changing coordination environment of the terpy site. The arbitrary thresholds of $K_{\mathrm{a}}>1300 \mathrm{M}^{-1}$ and $K_{\mathrm{a}}<600 \mathrm{M}^{-1}$ represent the requirements for the threaded state $(\mathrm{ON})$ and unthreaded state $(\mathrm{OFF})$, respectively. In this experiment the equilibrium mixture containing the free [2]pseudorotaxane ligand [26•N] ${ }^{3+}$ was reacted with $\mathrm{AgBF}_{4}$ in $\mathrm{CD}_{3} \mathrm{CN}$ to give pseudorotaxane 29 i.e. $\left[\mathrm{Ag}\left(\mathrm{CD}_{3} \mathrm{CN}\right)(\mathbf{2 6} \cdot \mathbf{N})\right]^{4+}$, designated as the $\mathrm{ON}$ state. Upon treatment of this complex with $\mathrm{CdCl}_{2} \bullet 6 \mathrm{H}_{2} \mathrm{O}$, the [2]pseudorotaxane 30, i.e. $\left[\mathrm{Cd}(\mathbf{2 6} \cdot \mathbf{N})_{2}\right]^{8+}$ was formed, it was designated as the OFF state.

The subsequent treatment of the OFF state with cyclam resulted in the removal of the $\mathrm{Cd}^{2+}$ ion and regeneration of the free ligand $[\mathbf{2 6} \cdot \mathbf{N}]^{3+}$ which by adding $\mathrm{AgBF}_{4}$ could restore the $\mathrm{ON}$ state. This procedure leads to the ON/OFF system, controllable by the coordination environment of the metal ion.

The above results have shown that the geometry of the metal coordination site can be used to monitor the association constant $K_{\mathrm{a}}$ for formation of [2]pseudorotaxanes; when the metal ions are exchangeable, and the ring is sufficiently large (as $\mathbf{N}$ ), the control of ON/OFF threading is possible. It should be pointed out that such control involving coordination of metal ions is promising for design of molecular switches (Scheme 13). ${ }^{76}$ 


\section{$[26 \cdot \mathbf{N}]$}
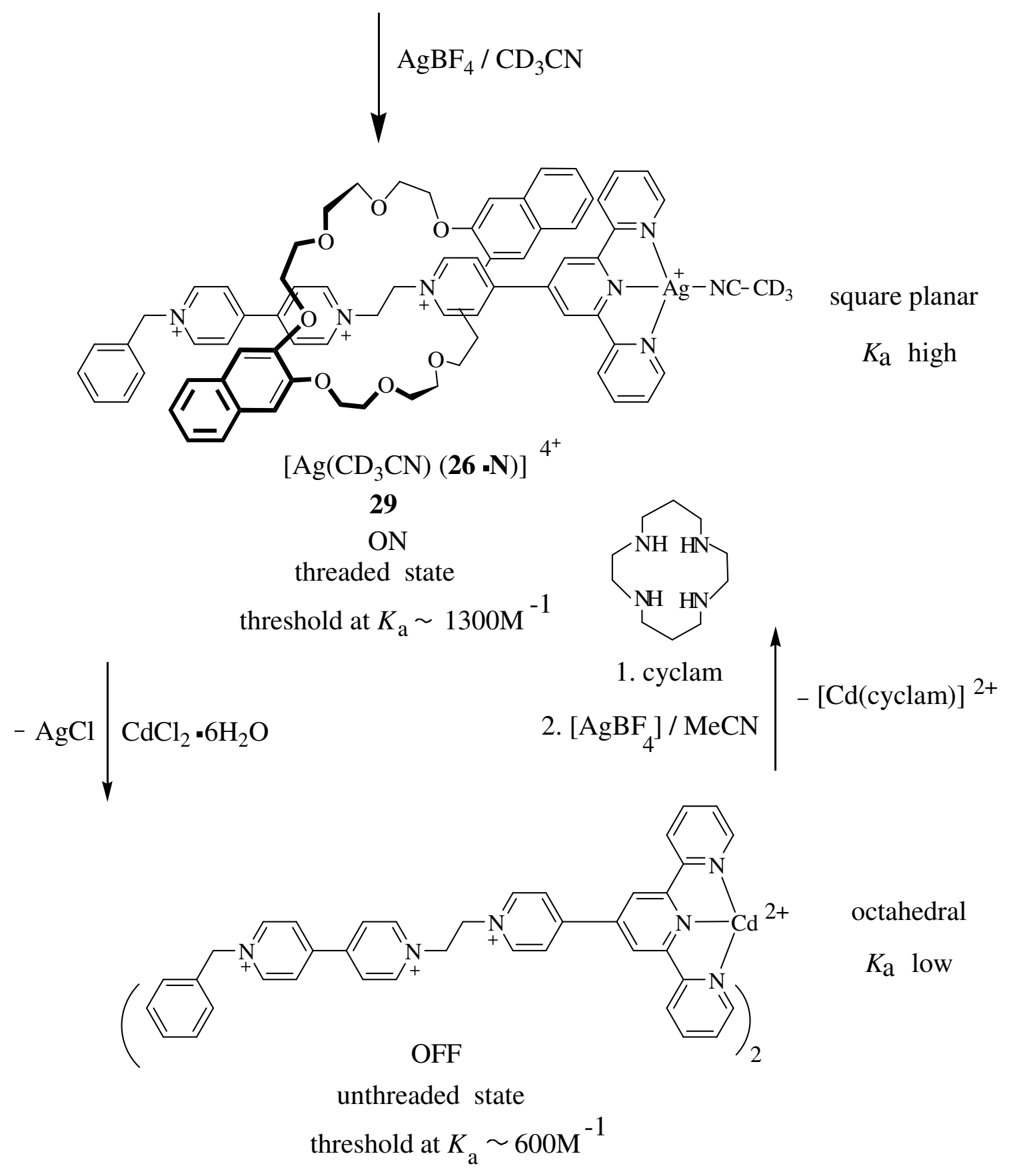

\section{Scheme 13}

In the study of complexation of viologens 31-33 with crown ethers, it was established that this process can be considerably enhanced by introduction of ion-pair recognition via the presence of 
urea units in the crown ether; this improvement is controlled by the nature of the viologen anions. $^{79}$

Due to the ion-pair recognition, the host can increase its binding affinity, and in some cases may even change its binding selectivity. One should point out the crucial role of ion-pair recognition in biological and analytical applications. ${ }^{80,81}$ It is noteworthy that the improvement of the binding affinity of viologens is very important for preparation of large supramolecular systems (Scheme 14).

In the experiments the heteroditopic receptor $\mathbf{3 4}$ was used as a ring, it contains the crown ether unit for binding the dicationic bipyridinium part of viologens 31-33 and two urea units for binding the two anions of these viologens. The complexation of 31-33 which have different anions with the crown ether $\mathbf{3 4}$ was investigated with the aim to improve the binding affinity of viologens. Crown ether $\mathbf{3 5}$ served here for comparative purposes.

It was found that complexes of $\mathbf{3 1 - 3 3}$ with $\mathbf{3 4}$ have the 1:1 stoichiometry in solution and they have higher $K_{\mathrm{a}}$ values than corresponding complexes with 35; this behavior results from the ionpair recognition. One should note that the $K_{\mathrm{a}}$ values for complexes of 31-33 with 34 are different, this fact indicates the different binding strengths of different anions of 31-33 with the urea groups of $34 .^{79}$

The experiments show that the complexes of $\mathbf{3 1}$ and $\mathbf{3 2}$ with $\mathbf{3 4}$ are in the solid state the taco complexes, in which the bipyridinium part of $\mathbf{3 1}$ or $\mathbf{3 2}$ is sandwiched between two aromatic rings of the crown ether moiety in $\mathbf{3 4}$. However, 33•34 is not a taco complex in the solid state, but is a pseudorotaxane, in which the bipyridinium part of $\mathbf{3 3}$ is encircled by the crown ether $\mathbf{3 4}$. This result was unexpected, since $\mathbf{3 1 \cdot 3 4}$ and $\mathbf{3 2 \cdot 3 4}$, as well as previously reported host-guest complexes consisting of viologens and BMP32C10 ${ }^{82}$ have the taco structure in the solid state.

The above described viologen/crown ether complexation, easily controlled by changing viologen anions is promising in design of molecular machines.

The crown-based lariat ethers are widely used in preparation of membranes and cationconducting channels, ${ }^{83-88}$ however their complexation with viologens has been only rarely reported. It was found that viologens $\mathbf{3 1}$ and $\mathbf{3 6}$ form pseudorotaxanes with lariat ether $\mathbf{3 7}$ in the solid state. One should note that viologen 31 affords with lariat ether $\mathbf{3 7}$ more stable pseudorotaxane than with the corresponding crown ether 38, i.e. BMP26C8; the $K_{\mathrm{a}}$ value for 31.37 i.e. A is ca 13 times higher than $K_{\mathrm{a}}$ for $\mathbf{3 1 \cdot 3 8}$ in solution, due to the presence of two benzyloxy groups in $\mathbf{3 7}$.

On the other side, comparing the association constant values of different viologens $\mathbf{3 1}$ and 36 with crown ethers, it was observed that $\mathbf{3 1}$ forms with $\mathbf{3 7}$ stronger pseudorotaxane $\mathbf{3 1} \cdot \mathbf{3 7}=\mathbf{A}$ than $\mathbf{3 6}$ does, forming $\mathbf{3 6} \cdot \mathbf{3 7}$, i.e. pseudorotaxane $\mathbf{B}$ (Scheme 15). ${ }^{89}$ 

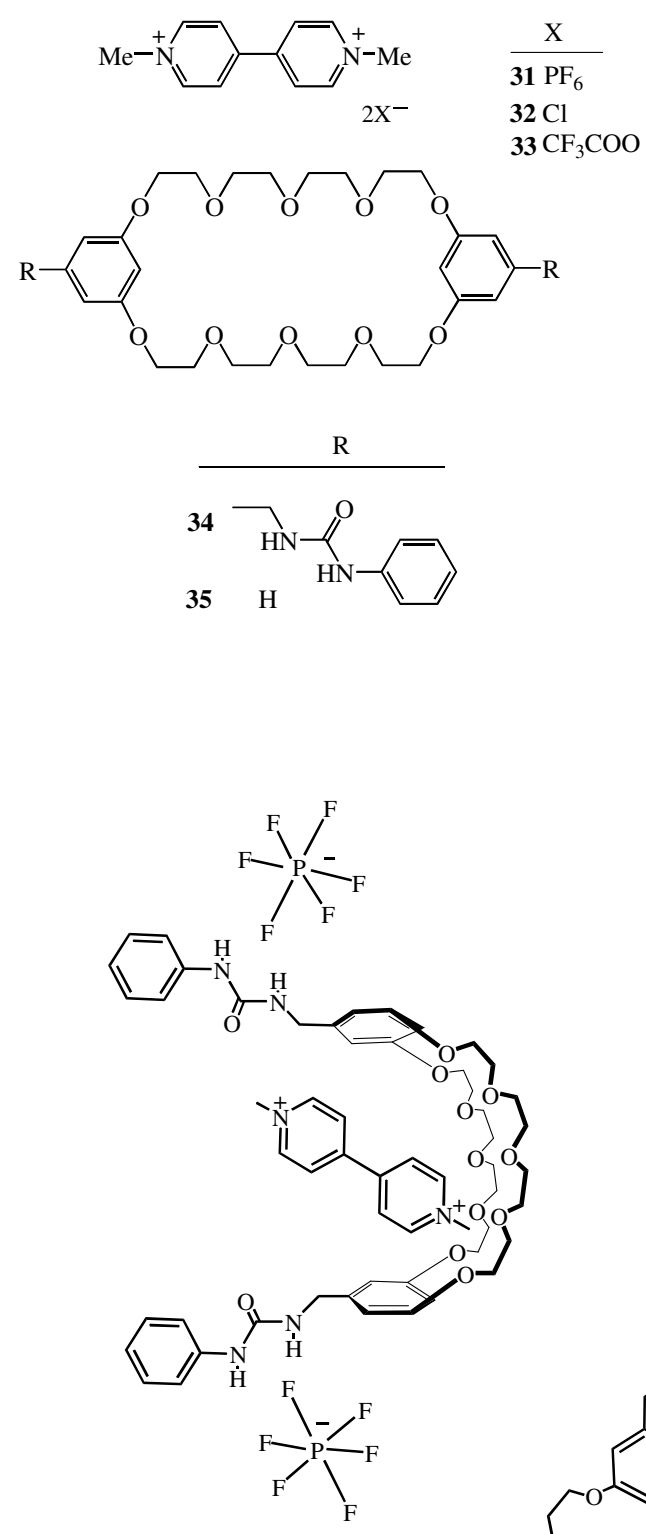
taco complex

$31 \cdot 34$

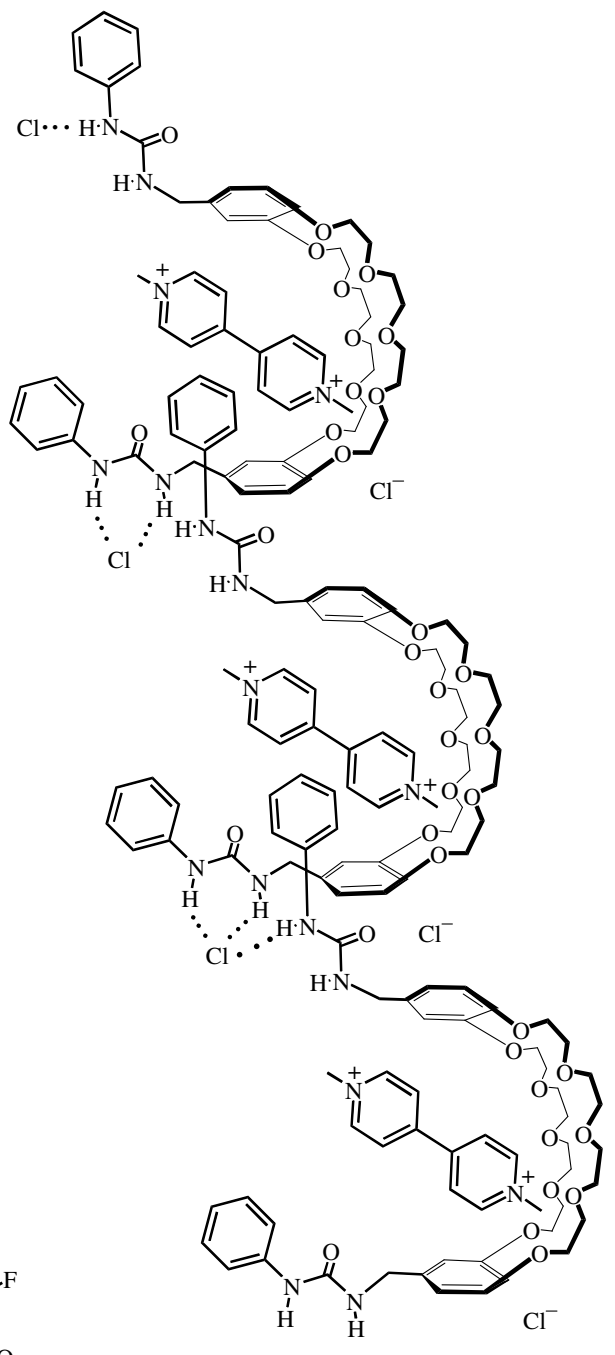

taco complex

$32 \cdot 34$

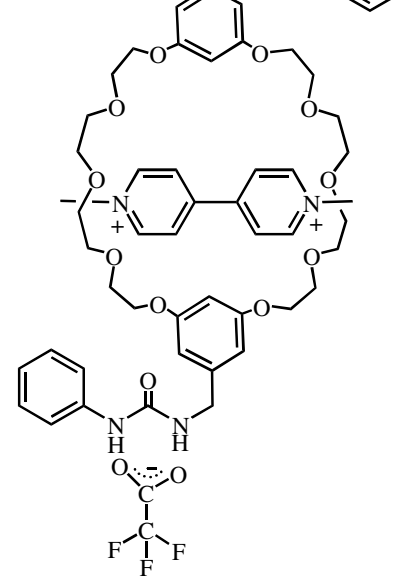

pseudorotaxane

$33 \cdot 34$

Scheme 14 

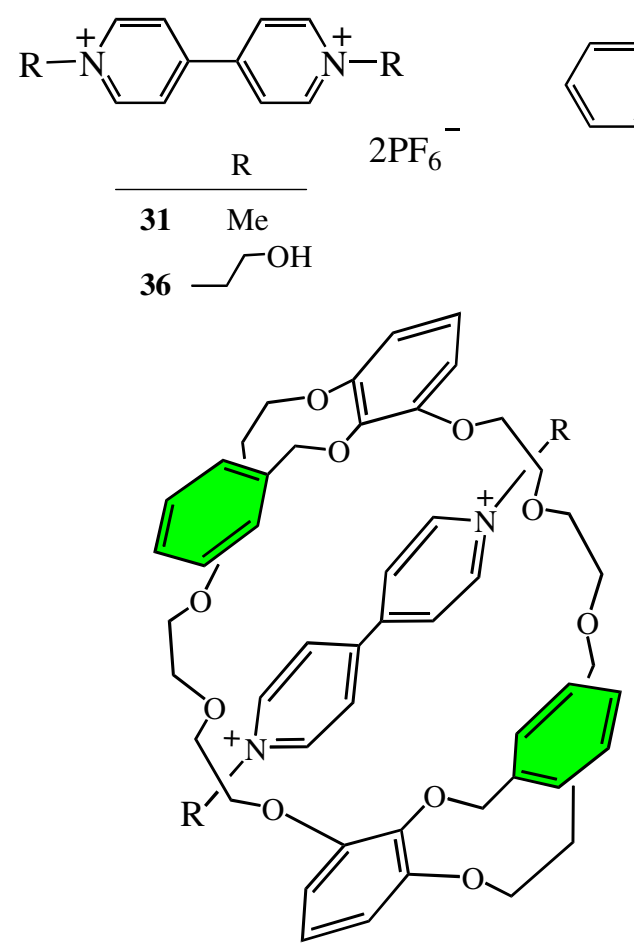

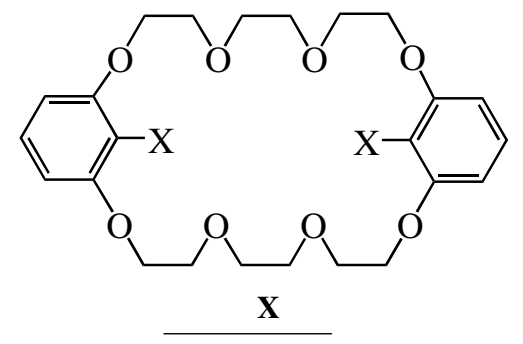

37 o

$38 \mathrm{H} \quad=$ BMP 26C8

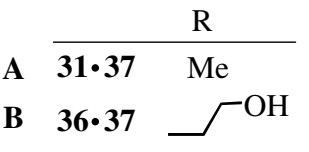

\section{Scheme 15}

Studying the crystal structures of both pseudorotaxanes, 31•37 (A) and 36•37 (B) it was found that in $\mathbf{A}$ and $\mathbf{B}$ the two pyridinium rings are coplanar, this behavior being not observed in other complexes of $\mathbf{3 1}$ with various crown ethers. ${ }^{90,91}$ The solid-state structures of $\mathbf{A}$ and $\mathbf{B}$ are stabilized by face-to-face $\pi$-stacking and charge transfer interactions between the four phenylene rings of $\mathbf{3 7}$ and the two pyridinium rings of $\mathbf{3 1}$ or $\mathbf{3 6}$. It was established that the benzyloxy groups in $\mathbf{3 7}$ enable an efficient face-to-face interactions with the pyridinium rings of viologens 31 and 36.

In the packing structure of $\mathbf{A}$ two pseudorotaxanes $\mathbf{A}$ are linked by a bridge consisting of two $\mathrm{PF}_{6}{ }^{-}$ions and one water molecule. In the packing structure of $\mathbf{B}$, however, four pseudorotaxanes $\mathbf{B}$ are linked by a $\mathrm{PF}_{6}^{-}$anion, each pair of pseudorotaxanes $\mathbf{B}$ being connected by hydrogen bonds of hydroxyethyl groups between two molecules of viologen 36, each included in the cavity of 37.

It was observed that lariat ether $\mathbf{3 7}$ can include the $\mathrm{K}^{+}$ions. The addition of $\mathrm{KPF}_{6}$ to $\mathbf{A}$ resulted in its dissociation, since $\mathrm{K}^{+}$replaced the viologen $\mathbf{3 1}$ as the guest of $\mathbf{3 7}$. However, the subsequent addition of crown ether DB18C6 caused the inclusion of $\mathrm{K}^{+}$into DB18C6, followed by restoration of pseudorotaxane A. Due to this fact the $\mathrm{K}^{+}$ions and DB18C6 may be used as a switch to control the association of viologen $\mathbf{3 1}$ with lariat ether $\mathbf{3 7}$, it is noteworthy that the dissociation percentage depends on the concentration of added $\mathrm{K}^{+}$ions.

The same process with the use of pseudorotaxane $\mathbf{B}$ has shown that for dissociation of $\mathbf{B}$ a smaller amount of $\mathrm{KPF}_{6}$ was required than for dissociation of $\mathbf{A}$, because $K_{\mathrm{a}}$ of $\mathbf{B}$ is lower than $K_{\mathrm{a}}$ 
of A. The obtained experimental results reveal that the $N$-substitution of viologens strongly influences the association strength between viologens $\mathbf{3 1}$ or $\mathbf{3 6}$ with lariat ether $\mathbf{3 7 .}$

\section{Rotaxanes and pseudorotaxanes containing crown-based cryptand as a ring}

\subsection{Rotaxanes}

It is known that compounds serving as threads, containing viologen units form with crown-based cryptands the rotaxanes of higher association constants than rotaxanes formed with crown ethers. It should be pointed out that rotaxanes with crown-based cryptands as rings, are not so thoroughly studied as those containing crown ether rings. Below rotaxanes with crown-based cryptands as rings will be described.

The synthesis of [2] rotaxanes 39 and $\mathbf{4 0}$ consisting of viologens $\mathbf{4 1}$ and bis( $m$-phenylene)-32crown-10-based cryptands $\mathbf{4 2}$ and $\mathbf{4 3}$, respectively, was performed using a threading-followedby-stoppering method. For rotaxane 39, as stoppers the tris(4-methoxyphenyl)phosphine groups were used, however, for rotaxane $\mathbf{4 0}$ the triphenylphosphine groups showed to be big enough to serve as stoppers (Scheme 16a).
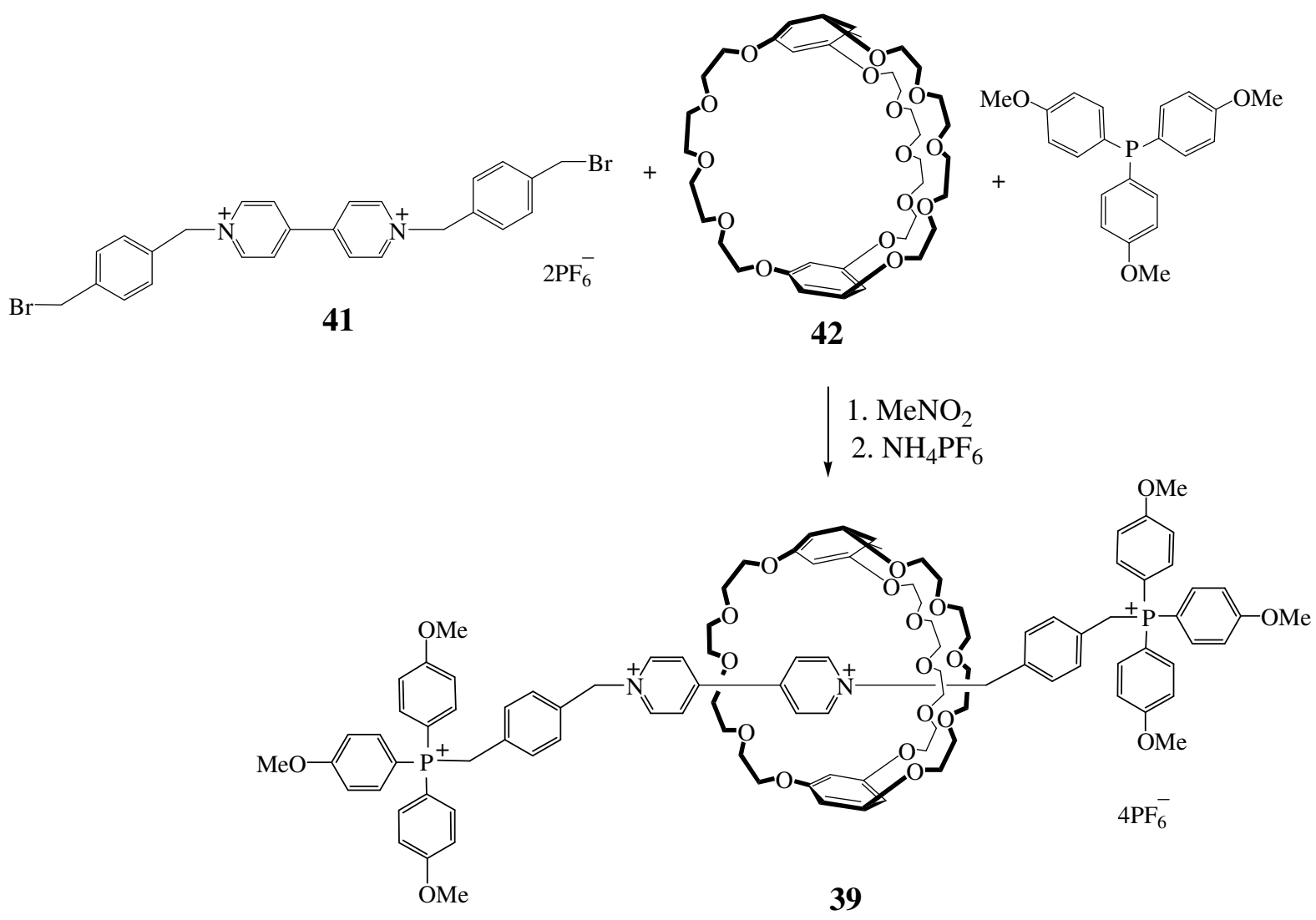

\section{Scheme 16a}


Syntheses of 39 and 40 were carried out by reacting viologen derivative 41 with cryptands 42 and 43 and tris(4-methoxyphenyl)phosphine or triphenylphosphine, respectively, in $\mathrm{MeNO}_{2}$. It should be pointed out that association constants between viologens and cryptands are high, therefore even in dilute solutions high yields of rotaxanes were achieved (Scheme 16b). ${ }^{92}$

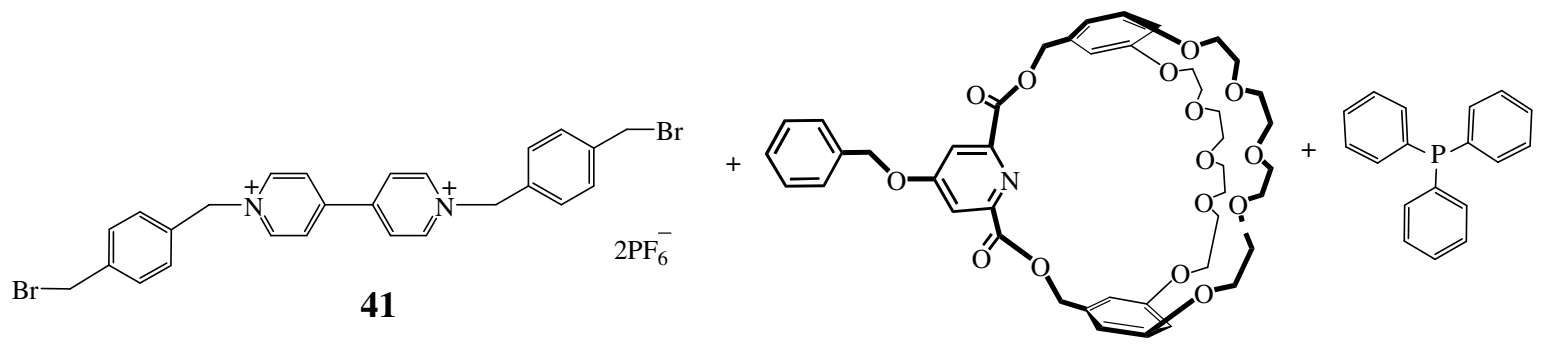

43

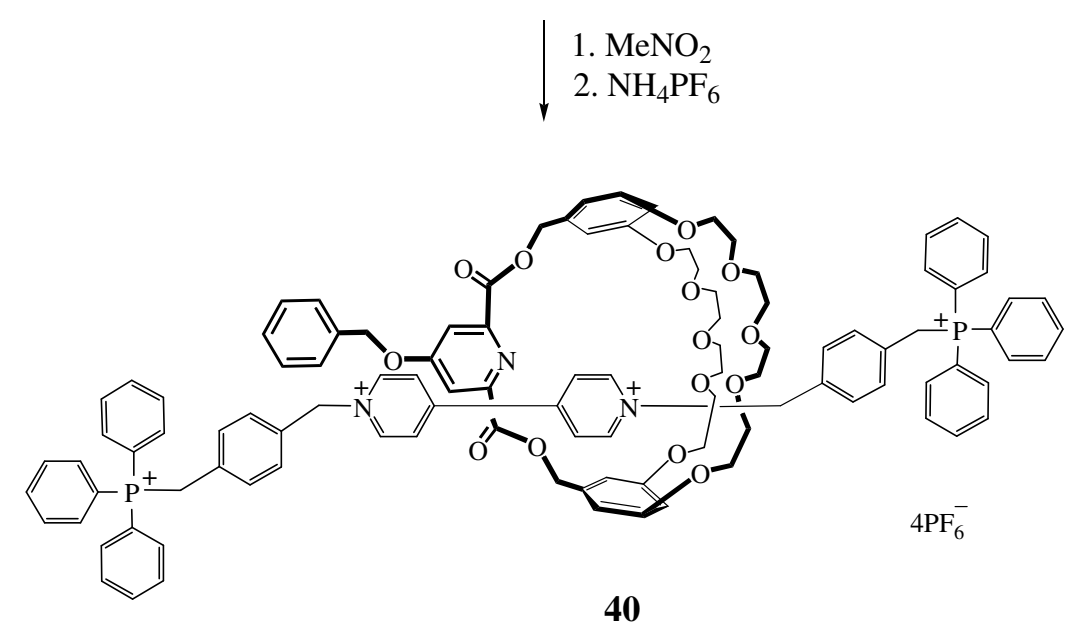

\section{Scheme 16b}

Two [2]rotaxanes $\mathbf{4 4}$ and $\mathbf{4 5}$ have been synthesized using the immediate solvent evaporation method (ISEM). ${ }^{93}$ It was observed that this procedure considerably accelerates organic reactions as compared to the conventional solution conditions, since the acceleration is due to enhancement of molecule-to-molecule contacts between reactants. One should point out that the yields of reactions performed by ISEM method are not lower than those obtained in conventional processes.

Syntheses of rotaxanes $\mathbf{4 4}$ and $\mathbf{4 5}$ are based on acylation reactions, i.e. the urethane formation and the esterification, respectively. ${ }^{94}$ For this purpose viologen 36 was mixed in acetonitrile with cryptand 46 and with 3,5-dimethylphenyl isocyanate used to form stoppers, and a catalytic amount of dibutyltin dilaureate was added, the subsequent evaporation yielded a film, which after purification by flash column chromatography afforded rotaxane 44 . By the same procedure, using 3,5-dimethylbenzoic anhydride to form stoppers, and a catalytic amount of trimethylphosphine as a base, the rotaxane $\mathbf{4 5}$ was prepared (Scheme 17). 

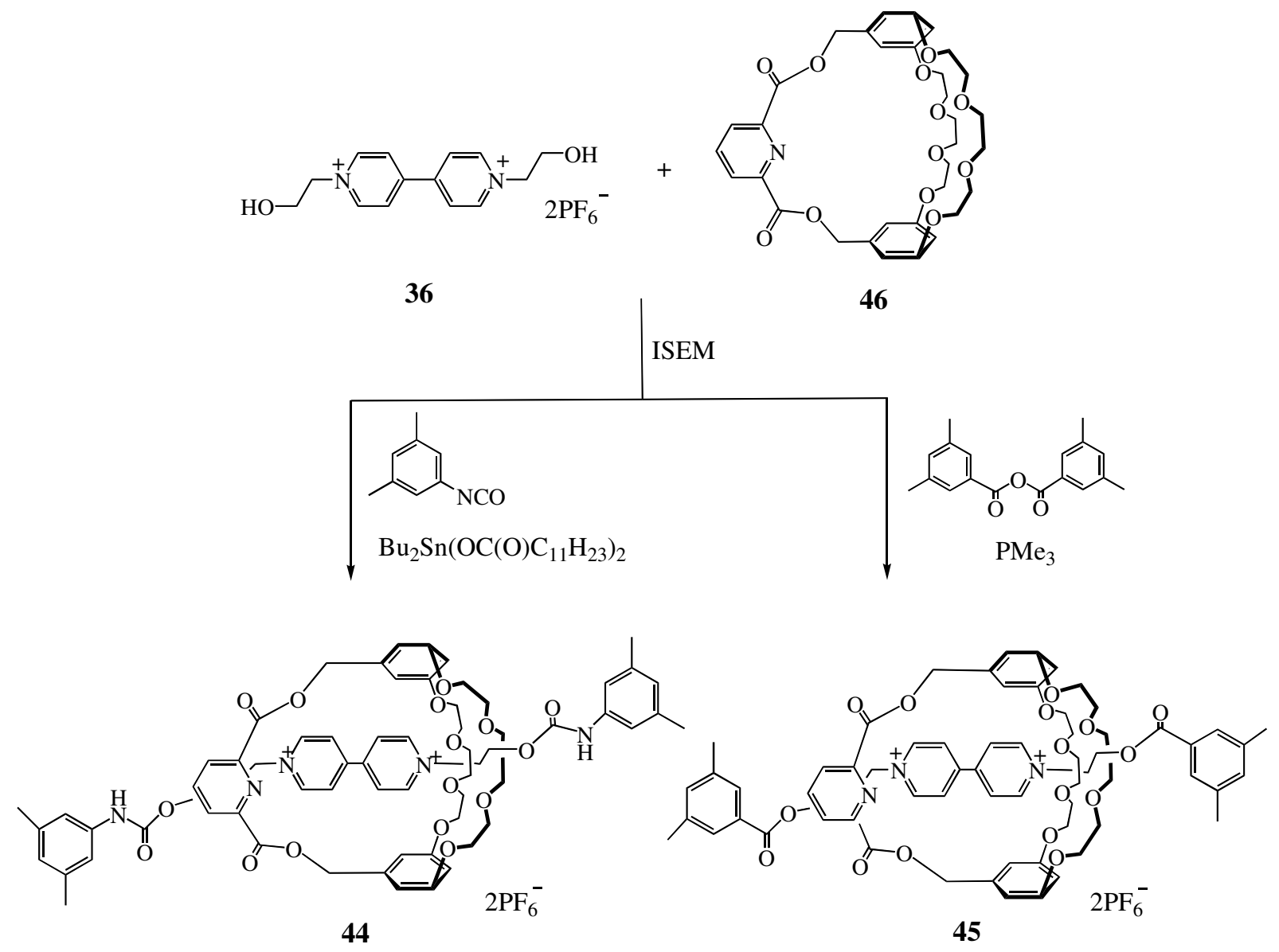

\section{Scheme 17}

Two [3]rotaxanes, 47 and 48 consisting of the thread 49 containing two viologen units and of bis(m-phenylene)-32-crown-10-based cryptands $\mathbf{4 2}$ and 43, respectively, have been obtained using the threading-followed-by-stoppering procedure. ${ }^{95}$ The reaction of bisviologen derivative 49 with cryptand 42 and tris(4-methoxyphenyl)phosphine afforded [3] rotaxane 47, whereas the same procedure, but with cryptand $\mathbf{4 3}$ and triphenylphosphine gave rise to [3] rotaxane 48 (Scheme 18). 

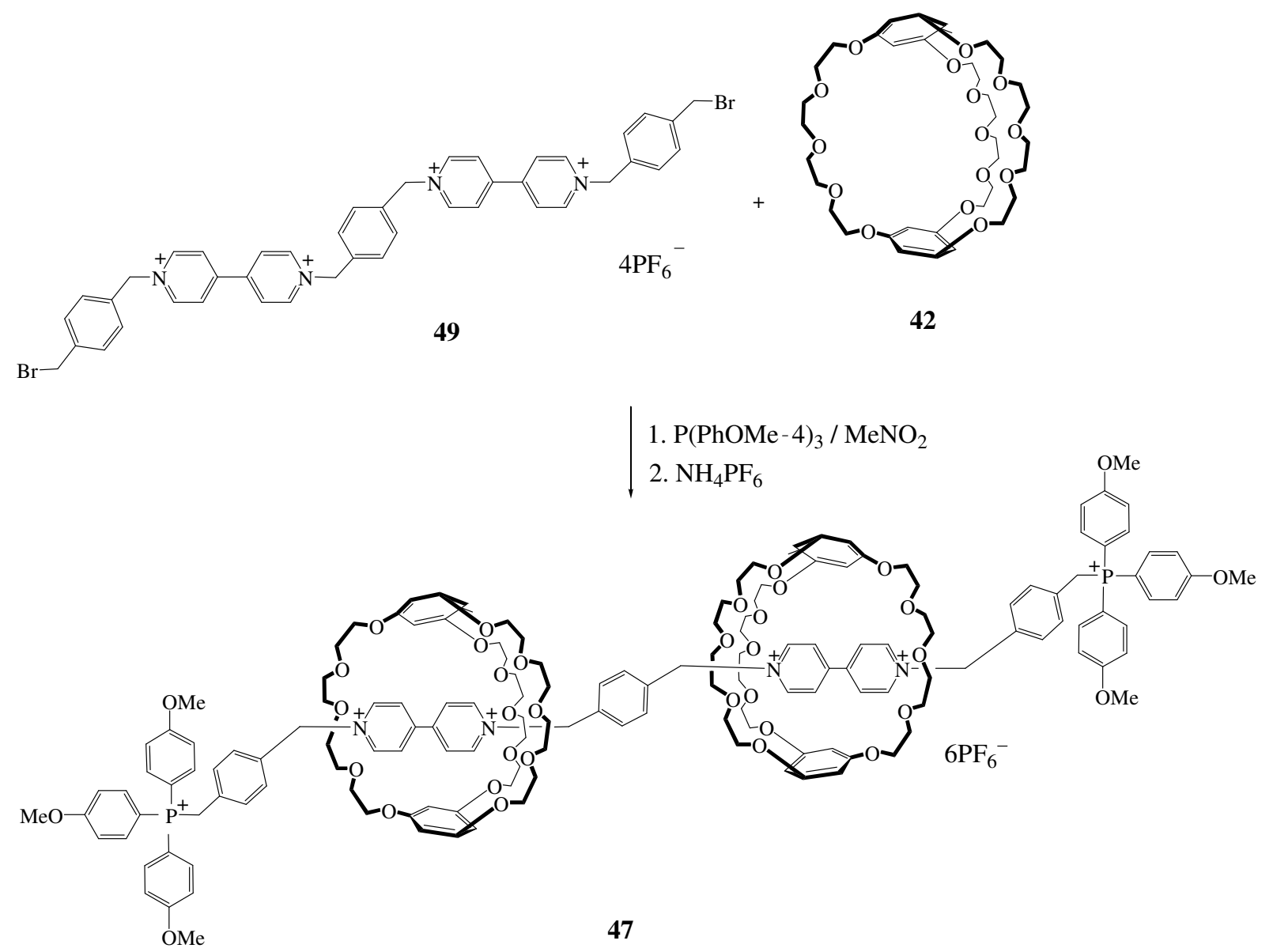

\section{Scheme 18}

One should mention that the synthesis of [3] rotaxanes is more difficult than synthesis of [2]rotaxanes. It is known that in the case of cooperative complexation between components, existing in formation of [3] rotaxanes or higher order rotaxanes, the yields of [2] rotaxanes are very low, this fact is advantageous for the synthesis of higher order rotaxanes. In the preparation of [3] rotaxanes $\mathbf{4 7}$ and $\mathbf{4 8}$ even in dilute solutions, the strong association and the cooperative complexation between the thread 49 and two cryptands exist, therefore no [2] rotaxanes are formed, and as a result, the [3]rotaxanes $\mathbf{4 7}$ and $\mathbf{4 8}$ are obtained in high yields (Scheme 19). ${ }^{95}$ 


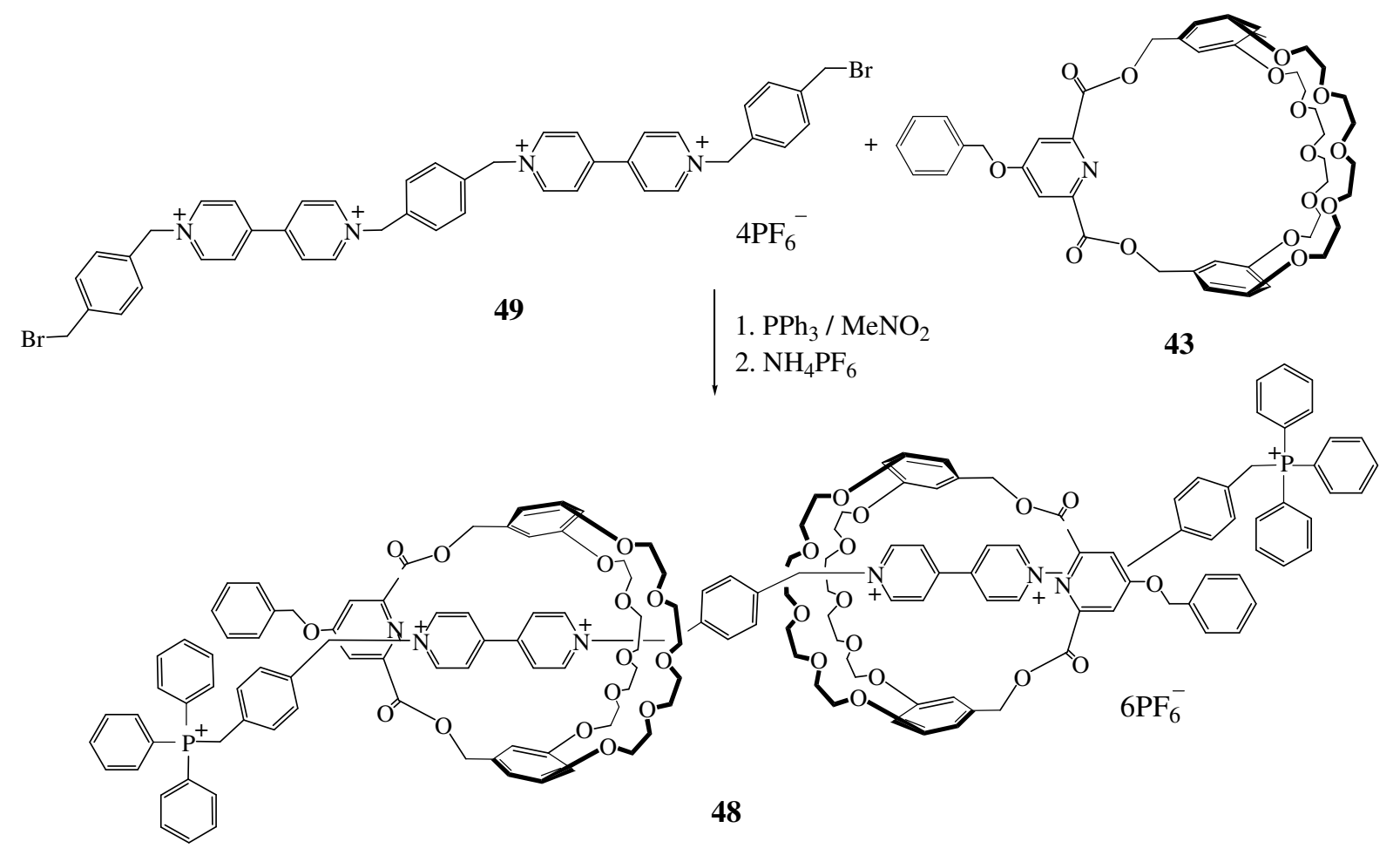

\section{Scheme 19}

\subsection{Pseudorotaxanes}

Pseudorotaxanes with threads containing viologen units and crown-based cryptand as a ring are, similarly as corresponding rotaxanes, more strongly bound than pseudorotaxanes with crown ether rings; some examples are shown below.

In the study of interaction of viologens 31, 50 and 36 with cryptand 51 it was found that 31 and $\mathbf{5 0}$ which are methyl substituted, form with $\mathbf{5 1}$ the inclusion complexes of T-shape $\mathbf{3 1 \cdot 5 1}$ and 50•51, while 36 which is not methyl substituted forms with $\mathbf{5 1}$ the symmetrically threaded pseudorotaxane 36•51 (Scheme 20).

In methyl substituted viologens 31 and 50, the hydrogen bonding with the electron rich oxygen atoms of $\mathbf{5 1}$ exists, therefore inclusion complexes $\mathbf{3 1 \cdot 5 1}$ and $\mathbf{5 0 . 5 1}$ are stronger than the pseudorotaxane $\mathbf{3 6} \cdot \mathbf{5 1}$, in which no hydrogen bonds with oxygen atoms of $\mathbf{5 1}$ are present. It was found that the $K_{\mathrm{a}}$ values decrease in the order $\mathbf{3 1} \cdot \mathbf{5 1}>\mathbf{5 0} \cdot \mathbf{5 1} \geq \mathbf{3 6} \cdot \mathbf{5 1}$. The experimental results were confirmed by theoretical calculations. ${ }^{96}$

Describing pseudorotaxanes in which the cryptand serves as a ring, one should also pay an attention to those containing pseudocryptands, ${ }^{30-97,98}$ an example of such species is presented below. $^{99}$ In this study there was performed the synthesis of pseudocryptand-type [2]pseudorotaxane involving self-assembly of viologen $\mathbf{3 1}$ with crown ether $\mathbf{5 2}$ bearing two pyridyl units. In the product, $\mathbf{5 2}$ is folded and the two pyridyl units interact via off-set face-to-face $\pi$-stacking. The two nitrogen atoms of pyridyl units are pointed to the central cavity 
forming a pseudocryptand. Viologen $\mathbf{3 1}$ is threaded through the cavity of pseudocryptand affording pseudocryptand-type [2]pseudorotaxane $\mathbf{3 1 \cdot 5 2}$.

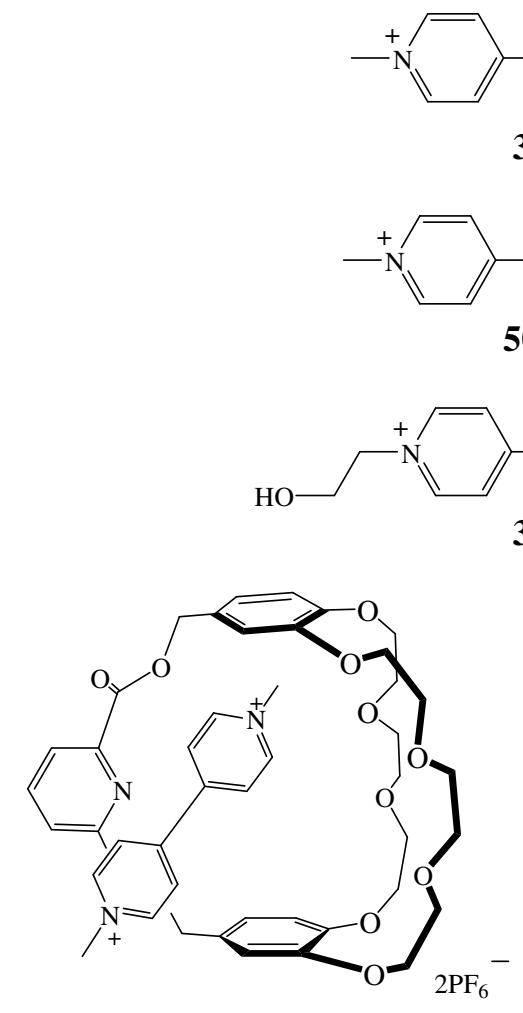

$31 \cdot 51$

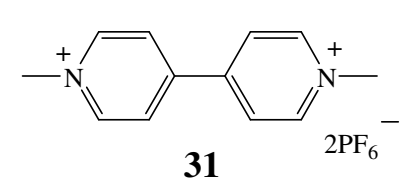

31

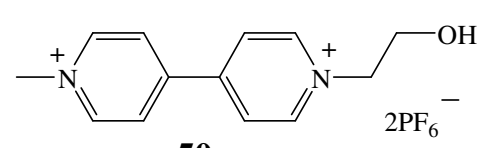

50

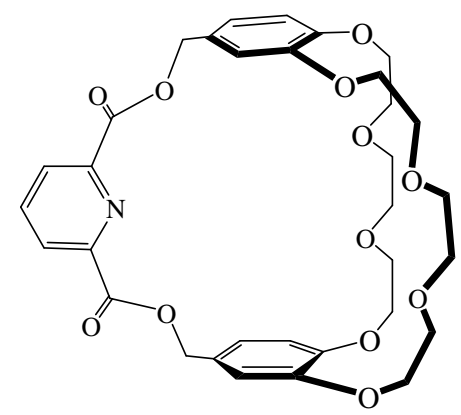

51

36

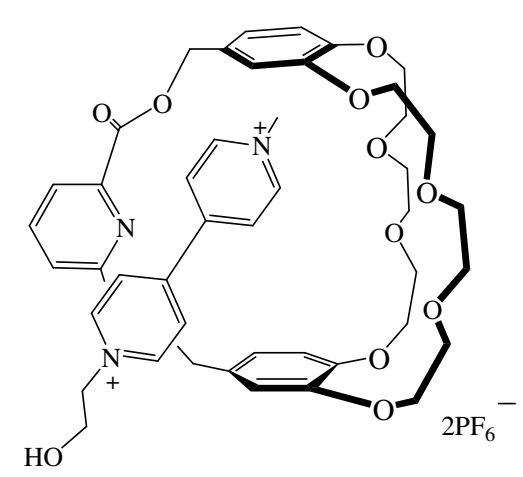

$50 \cdot 51$

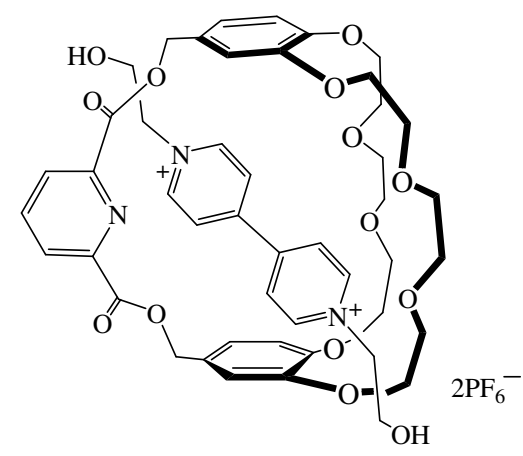

$36 \cdot 51$

\section{Scheme 20}

This pseudorotaxane is stabilized by hydrogen bonds of hydrogen atoms of $\mathbf{3 1}$ with oxygen and nitrogen atoms of $\mathbf{5 2}$ and by off-set face-to-face $\pi$-stacking between pyridinium rings of $\mathbf{3 1}$ and phenylene rings of $\mathbf{5 2}$.

It was found that the opening and closing of the pseudocryptand noncovalent linkage (i.e. the third pseudo-bridge) in $\mathbf{3 1 . 5 2}$ can be controlled owing to the basicity of pyridine units. The addition of TFA results in the opening of the pseudocryptand and formation of the taco complex 31.52 (TFA) 2 , whereas the addition of triethylamine causes the recovery of the pseudocryptand-type [2]pseudorotaxane 31.52. These experiments indicate that the opening and closing of the linkage of pyridyl units acts under acid-base control (Scheme 21). ${ }^{99}$

It should be pointed out that the formation of the third pseudo-bridge of pseudocryptand via the H-bonding of 31 with pyridyl units of 52 and the $\pi$-stacking increases the association constant of the pseudocryptand-type [2]pseudorotaxane $31 \cdot 52$ nearly threefold as compared to association constant of complexation of $\mathbf{3 1}$ with unsubstitutd BMP32C10. An interesting feature of the pseudocryptand-type [2]pseudorotaxane $\mathbf{3 1 . 5 2}$ is the fact that it has the acid-base 
adjustable association constant; this for the first time observed behavior is possible due to the basicity of pyridyl groups, which form the third pseudo-bridge.

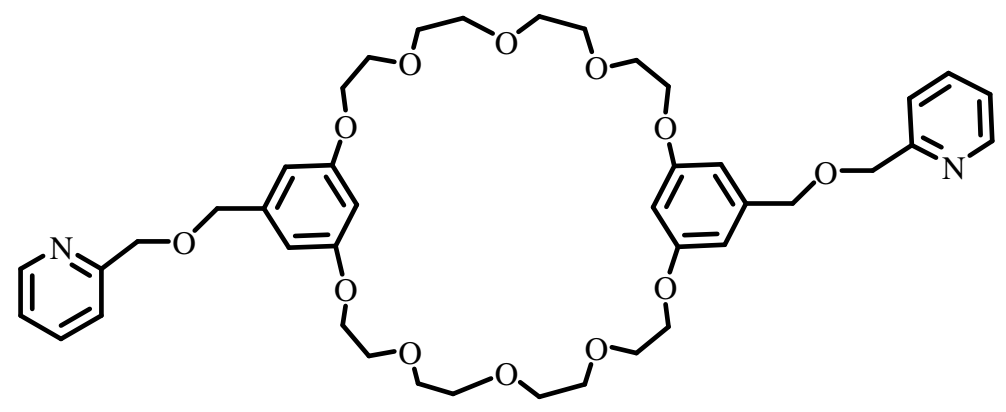

52
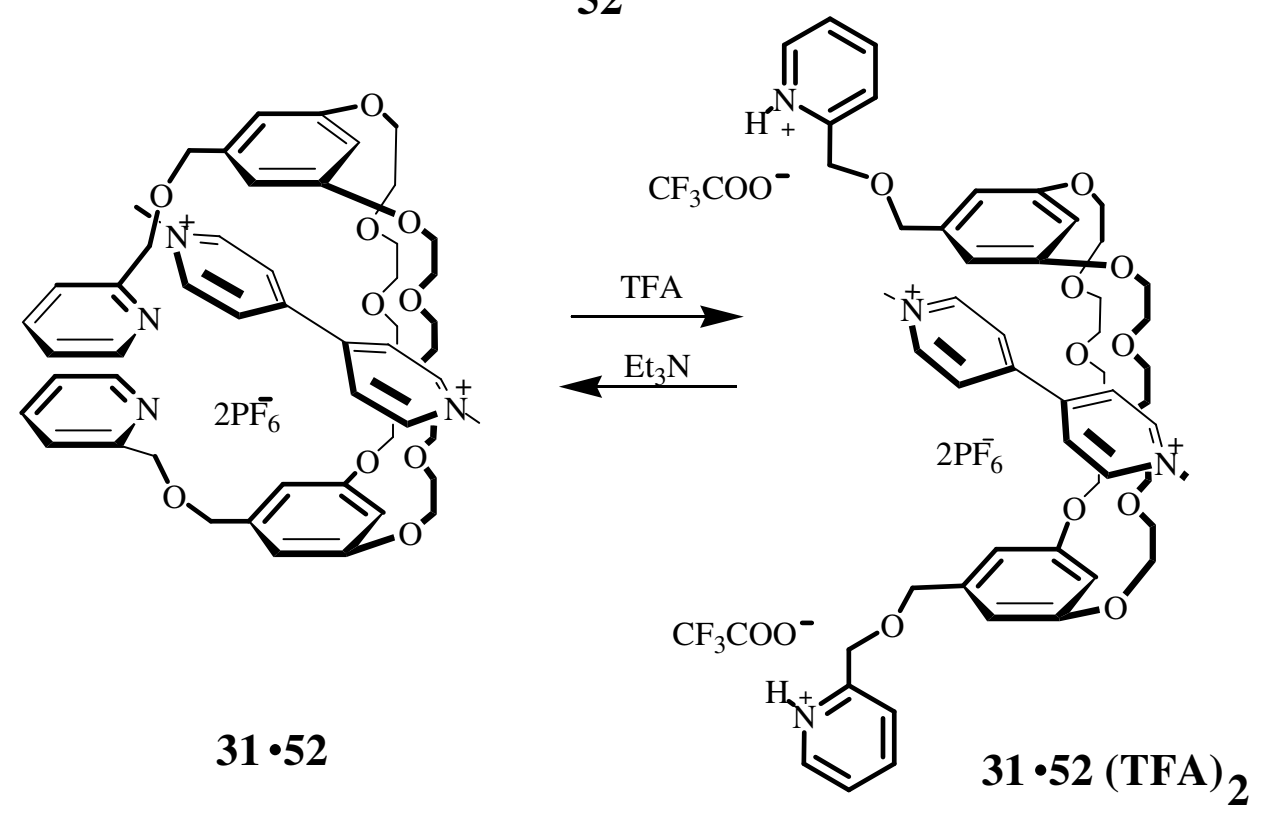

pseudocryptand-type taco complex

[2]pseudorotaxane

\section{Scheme 21}

Studying the interaction of viologens 53a,f with the large triptycene-based macrotricyclic host 54 it was established that the kind of obtained stable pseudorotaxane-type complexes depends on the structure of viologens.

Among investigated species, the viologens 53 a-d bearing alkyl groups are threading both lateral crown units of $\mathbf{5 4}$ to give 1:1 pseudorotaxane-type complexes A; here the complex $\mathbf{5 3 c} \cdot 54$ is shown. However viologens 53e,f bearing $\beta$-hydroxyethyl and $\gamma$-hydroxypropyl groups, respectively, thread (as two molecules 53e or 53f) the central cavity of $\mathbf{5 4}$ to give 2:1 pseudorotaxane-type complexes $\mathbf{B}$, here the complex $(\mathbf{5 3 e})_{2} \cdot 54$ is shown. It is noteworthy that complexes $\mathbf{A}$ and $\mathbf{B}$ are formed in solution and in solid state and are stable (Scheme 22). ${ }^{100}$ 


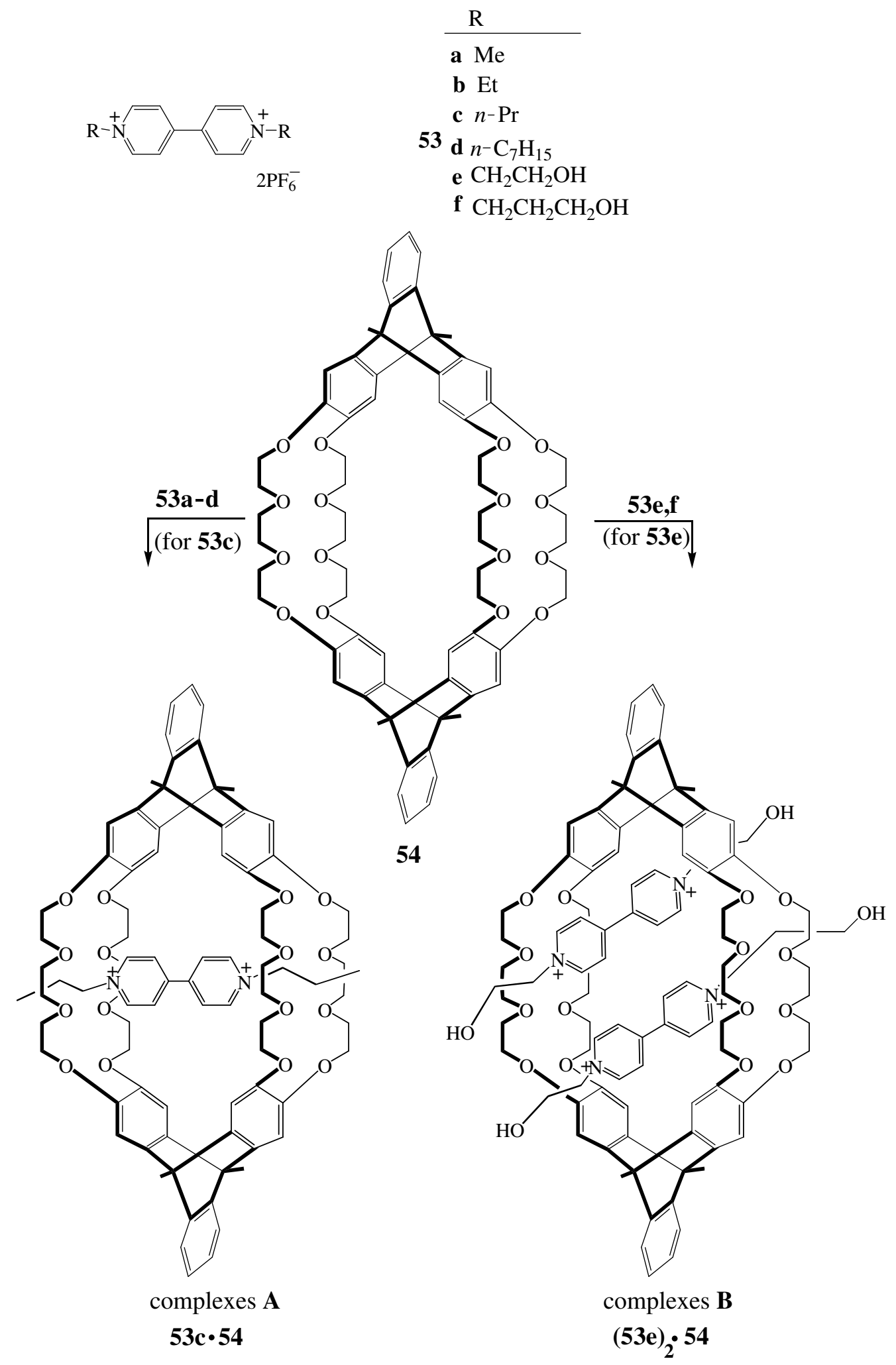

Scheme 22 


\section{Conclusions}

Today investigations concerning mechanically interlocked structures are rapidly developing. Having in view a multitude of works dealing with rotaxanes ${ }^{101-103}$ and pseudorotaxanes, ${ }^{104,105}$ as well as works concerning these both structures, ${ }^{106,107}$ in the present paper only selected examples are described.

Among a great number of applications of rotaxanes, such as construction of molecular devices or sensors, one should point out the possibility to use these species in the design of molecular machines. ${ }^{108-110}$

Recently an intense research of cyclodextrin-based rotaxanes is observed. ${ }^{111-114}$ One should mention here also pillarene-based pseudorotaxanes, ${ }^{115,116}$ they are a new class of supramolecular structures yet not so thoroughly studied as other, longer known species.

A growing attention is paid now to polyrotaxanes ${ }^{117,118}$ and polypseudorotaxanes ${ }^{119,120}$ which are a topic of increasing number of reports.

\section{Acknowledgements}

The work is a part of the project no. N N209 441539. The authors gratefully acknowledge Polish Ministry of Science along with Higher Education and National Science Centre for financial support.

\section{References}

1. Brown, A.; Beer, P. D. Dalton Trans. 2012, 41, 118.

2. Fioravanti, G. Curr. Org. Synth. 2012, 9, 199.

3. Friscic, T. Chem. Soc. Rev. 2012, 41, 3493.

4. Zhu, L.; Yan, H.; Nguyen, K. T.; Tian, H.; Zhao, Y. Chem. Comm. 2012, 48, 4290.

5. Zazza, C.; Mancini, G.; Brancato, G.; Sanna, N.; Barone, V. Comp. Theor. Chem. 2012, 985, 53.

6. Fernando, I. R.; Mezei, G. Inorg. Chem. 2012, 51, 3156.

7. Mukhopadhyay, C.; Ghosh, S.; Schmiedekamp, A. M. Org. Biomol. Chem. 2012, 10, 1434.

8. Lu, Y.; Li, H.; Zhu, X.; Liu, H.; Zhu, W. Int. J. Quantum Chem. 2012, 112, 1421.

9. Hansen, S. W.; Stein, P. C.; Soerensen, A.; Share, A. I.; Witlicki, E. H.; Kongsted, J.; Flood, A. H.; Jeppesen, J. O. J. Am. Chem. Soc. 2012, 134, 3857.

10. Beves, J. E.; Blight, B. A.; Cambell, C. J.; Leigh, D. A.; McBurney, R. T. Angew. Chem. Int. Ed. 2011, 50, 9260.

11. Stoddart, J. F. Chem. Soc. Rev. 2009, 38, 1802. 
12. Caballero, A.; Zapata, F.; White, N. G.; Costa, P. J.; Felix, V.; Beer, P. D. Angew. Chem. Int. Ed. 2012, 51, 1876.

13. Cougnon, F. B. L.; Jenkins, N. A.; Pantos, G. D.; Sanders, J. K. M. Angew. Chem. Int. Ed. 2012, 51, 1443.

14. Chas, M.; Ballester, P. Chem. Sci. 2012, 3, 186.

15. Lanari, D.; Bonollo, S.; Vaccaro, L. Curr. Org. Synth. 2012, 9, 188.

16. Guo, J.; Mayers, P.C.; Breault, G. A.; Hunter, C. A. Nature Chem. 2010, 2, 218.

17. Peinador, C.; Blanco, V.; Quintela, J. M. J. Am. Chem. Soc. 2009, 131, 920.

18. Forgan, R. S.; Wang, C.; Friedman, D. C.; Spruell, J. M.; Stern, C. L.; Sarjeant, A. A.; Cao, D., Stoddart, J. F. Chem. Eur. J. 2012, 18, 202.

19. Evans, N. H.; Beer, P. D. Chem. Eur. J. 2011, 17, 10542.

20. Li, F.; Cregg, J.K.; Lindoy, L. F.; Macquart, R. B.; Meehan, G. V. Nat. Commun. 2011, 2, 205.

21. Yang, W.; Li, Y.; Liu, H.; Chi, L.; Li,Y. Small 2012, 8, 504.

22. Balzani, V.; Semeraro, M.; Venturi, M.; Credi, A. in Molecular Switches 2nd. Ed., 2011, Feringa, B. L.; Browne, W. R. Eds., Wiley-VCH: Weinheim, Vol. 2, 597.

23. Bodis, P.; Yeremenko, S.; Berna, J.; Buma, W. J.; Leigh, D. A.; Woutersen, S. J. Chem. Phys. 2011, 134, 134504.

24. Lussis, P.; Svaldo-Lanero, T.; Bertocco, A.; Fustin, C.-A.; Leigh, D. A.; Duwez, A.-S. Nat. Nanotechnol. 2011, 6, 553.

25. Yan, X.; Zhou, M.; Chen, J.; Chi, X.; Dong, S.; Zhang, M.; Ding, X.; Yu, Y.; Shao, S.; Huang, F. Chem. Commun. 2011, 47, 7086.

26. Niu, Z.; Huang, F.; Gibson, H. W. J. Am. Chem. Soc. 2011, 133, 133.

27. Tuncel, D.; Uenal, O.; Artar, M. Isr. J. Chem. 2011, 51, 525.

28. Vedernikov, A. I.; Lobova, N. A.; Kuzmina, L. G.; Howard, J. A. K.; Strelenko, Y. A.; Alfimov, M. V.; Gromov, S. P. J. Mol. Struct. 2011, 989, 114.

29. Briggs, B. N.; Durola, F.; McMillin, D. R.; Sauvage, J.-P. Can. J. Chem. 2011, 89, 98.

30. Niu, Z.; Slebodnick, C.; Gibson, H. W. Org. Lett. 2011, 13, 4616.

31. Fernando, I. R.; Bairu, S. G.; Ramakrishna, G.; Mezei, G. New J. Chem. 2010, 34, 2097.

32. Li, J. J; Zhao, F.; Li, J. Appl. Microbiol. Biotechnol. 2011, 90, 427.

33. Girek, T. J. Incl. Phenom. Macrocycl. Chem. 2012, 74, 1.

34. Liu, P.; Chipot, C.; Shao, X.; Cai, W. J. Phys. Chem. C. 2012, 116, 4471.

35. Dumarcay-Charbonnier, F.; Marsura, A. Chem. Commun. 2012, 48, 732.

36. Arduini, A.; Bussolati, R.; Masseroni, D.; Royal, G.; Secchi, A. Eur. J. Org. Chem. 2012, 1033.

37. Leontiev, A. V.; Jemmett, C. A.; Beer, P. D. Chem. Eur. J. 2011, 17, 816.

38. Sinha, M. K.; Reany, O.; Yefet, M.; Botoshansky, M.; Keinan, E. Chem. Eur. J. 2012, 18, 5589.

39. Zhang, H.; Liu, L.; Gao, C.; Sun, R.; Wang, Q. Dyes Pigments 2012, 94, 266.

40. Sliwa, W.; Bachowska, B.; Girek, T. Curr. Org. Chem. 2012, 16, 1332. 
41. Ramalingam, V.; Urbach, A. R. Org. Lett. 2011, 13, 4898.

42. Ma, X.; Sun, R.; Li, W.; Tian, H. Polym. Chem. 2011, 2, 1068.

43. Boccia, A.; Lanzilotto, V.; Di Castro, V.; Zanoni, R.; Pescatori, L.; Arduini, A.; Secchi, A. Phys. Chem. Chem. Phys. 2011, 13, 4452.

44. Qu, D.-H.; Tian, H. Chem. Sci. 2011, 2, 1011.

45. Li, H.; Fahrenbach, A. C.; Coskun, A.; Zhu, Z.; Barin, G.; Zhao, Y.-L.; Botros, Y. Y.; Sauvage, J.-P.; Stoddart, J. F. Angew. Chem. Int. Ed. 2011, 50, 6782.

46. Lestini, E.; Nikitin, K.; Stolarczyk, J. K.; Fitzmaurice, D. Chem. Phys. Chem. 2012, 13, 797.

47. Hu, S.-Z.; Chen, C.-F. Chem. Eur. J. 2011, 17, 5424.

48. Jiang, W.; Wang, Q.; Linder, I.; Klautzsch, F.; Schalley, C.A. Chem. Eur. J. 2011, 17, 2344.

49. Niu, Z.; Slebodnick, C.; Bonrad, K.; Huang, F.; Gibson, H. W. Org. Lett. 2011, 13, 2872.

50. Tejerina, B.; Gothard, C.M.; Grzybowski, B. A. Chem. Eur. J. 2012, 18, 5606.

51. Ikeda, T.; Higuchi, M. Tetrahedron 2011, 67, 3046.

52. Basu, S.; Coskun, A.; Friedman, D. C.; Olson, M.A.; Benitez, D.; Tkatchouk, E.; Barin, G.; Yang, J.; Fahrenbach, A. C.; Goddart, W. A.; Stoddart, J. F. Chem. Eur. J. 2011, 17, 2107.

53. Hmadeh, M.; Fahrenbach, A. C.; Basu, S.; Trabolsi, A.; Benitez, D.; Li, H.; Albrecht-Gary, A.-M.; Elhabiri, M.; Stoddart, J. F. Chem. Eur. J. 2011, 17, 6076.

54. Constantin, V.-A.; Bongard, D.; Walder, L. Eur. J. Org. Chem. 2012, 913.

55. Park, J.-J.; Kim, Y.-H.; Rhim, S.; Kang, J. Tetr. Lett. 2012, 53, 247.

56. Freitag, M.; Gundlach, L.; Piotrowiak, P.; Galoppini, E. J. Am. Chem. Soc. 2012, 134, 3358.

57. Bonchio, M.; Carraro, M.; Casella, G.; Causin, V.; Rastrelli, F.; Saielli, G. Phys. Chem. Chem. Phys. 2012, 14, 2710.

58. Tuite, E. M.; Rose, D. B.; Ennis, P. M.; Kelly, J. M. Phys. Chem. Chem. Phys. 2012, 14, 3681 .

59. Porel, M.; Klimczak, A.; Freitag, M.; Galoppini, E.; Ramamurthy, V. Langmuir. 2012, 28, 3355.

60. Sliwa, W.; Chrzastek, L. Curr. Org. Chem. 2009, 13, 339.

61. Raiteri P.; Bussi, G.; Cucinotta, C. S.; Credi, A.; Stoddart, J. F.; Parrinello, M. Angew. Chem. Int. Ed. 2008, 47, 3536.

62. Wu J.; Leung K.C.-T.; Benitez, D.; Han, J.-Y.; Cantrill, S. J.; Fang, L.; Stoddart, J. F. Angew. Chem. Int. Ed. 2008, 47, 7470.

63. Frogan, R. S.; Sauvage, J.-P.; Stoddart, J. F. Chem. Rev. 2011, 111, 5434.

64. Zheng, B.; Wang, F.; Dong, S.; Huang, F. Chem. Soc. Rev. 2012; 41, 1621.

65. Niu, Z.; Huang, F.; Gibson, H. W. J. Am. Chem. Soc. 2011, 133, 2836.

66. Lee, M.; Moore, R. B.; Gibson, H. W. Macromolecules 2011, 44, 5987.

67. Dong, S.; Luo, Y.; Yan, X.; Zheng, B.; Ding, X.; Yu, Y.; Ma, Z.; Zhao, Q.; Huang F. Angew. Chem. Int. Ed. 2011, 50, 1905. 
68. Lee, Y.-G.; Koyama, Y.; Yonekawa, M.; Takata, T. Macromolecules 2010, 43, 4070.

69. Fang, L.; Olson, M.A.; Benitez, D.; Tkatchouk, E.; Goddard, W.A.; Stoddart, J. F. Chem. Soc. Rev. 2010, 39, 17.

70. Leung, K.C.-F.; Lau, K.-N. Polym. Chem. 2010, 1, 988.

71. Li, S.; Zheng, B.; Chen. J.; Dong, S.; Ma, Z.; Huang F.; Gibson, H. W. J. Polym. Sci. Part A: Polym. Chem. 2010, 48, 4067.

72. Zhang, M.; Li, S.; Dong, S.; Chen, J.; Zheng, B.; Huang, F. Macromolecules 2011, 44, 9629.

73. Altobello, S.; Nikitin, K.; Stolarczyk, J. K.; Lestini, E.; Fitzmaurice D. Chem. Eur. J. 2008, 14, 1107.

74. Nikitin, K.; Lestini, E.; Stolarczyk, J. K.; Müller-Bunz, H.; Fitzmaurice D. Chem. Eur. J. 2008, 14, 1117.

75. Lestini, E.; Nikitin, K.; Müller-Bunz, H.; Fitzmaurice D. Chem. Eur. J. 2008, 14, 1095.

76. Sharma, S.; Davidson, G. J. E.; Loeb, S. J. Chem. Commun. 2008, 582.

77. Champin, B.; Mobian, P.; Sauvage, J.-P. Chem. Soc. Rev. 2007, 36, 358.

78. Sobransingh, D.; Kaifer, A. E. Org. Lett. 2006, 8, 3247.

79. Zhu, K.; Li, S.; Wang, F.; Huang, F. J. Org. Chem. 2009, 74, 1322.

80. Lankshear, M. D.; Dudley, I. M.; Chan, K.-M.; Cowley, A. R.; Santos, S. M.; Felix, V.; Beer, P. D. Chem. Eur. J. 2008, 14, 2248.

81. Wintergerst, M. P.; Levitskaia, T. G.; Moyer, B. A.; Sessler, J. L.; Delmau, L. H. J. Am. Chem. Soc. 2008, 130, 4129.

82. Yang, Y.; Hu, H.-Y.; Chen, C. F. Tetrahedron Lett. 2007, 48, 3505.

83. Kozlowski, C. A.; Kozlowska, J. J. Membr. Sci. 2009, 326, 215.

84. Cragg, P. J.; Vahora, R. Supramol. Chem. 2012, 3, 733.

85. Maciejewski, P.; Ulewicz, M.; Robak, W.; Walkowiak, W. Int. J. of Environment and Waste Management 2011, 8, 305.

86. Bredikhina, Z. A.; Eliseenkova, R. M.; Fayzullin, R. R.; Novikova, V. G.;Kharlamov, S. V.; Sharafutdinova, D. R.; Latypov, S. K.; Bredikhin, A. A. Arkivoc 2011, 10, 1.

87. Penso, M.; Maia A.; Lupi, V.; Tricarico, G. Tetrahedron 2011, 67, 2096.

88. Rodriguez- Rodriguez, A.; Carreira-Barral, I.; Regueiro-Figueroa, M.; Esteban-Gomez, D.; Platas-Iglesias, C.; de Blas, A.; Rodriguez-Blas, T. Polyhedron 2012, 31, 402.

89. Zhang, M.; Luo, Y.; Zheng, B.; Xia, B.; Huang, F. Eur. J. Org. Chem. 2010, 5543.

90. Cao, D.; Amelia, M.; Klivansky, L. M.; Koshkakaryan, G.; Khan, S. I.; Semeraro, M.; Silvi, S.; Venturi, M.; Credi, A.; Liu, Y. J. Am. Chem. Soc. 2010, 132,1110.

91. Cao, J.; Lu, H.-Y.; Xiang, J.-F.; Chen, C.-F. Chem. Commun. $2010,3586$.

92. Li, S.; Liu, M.; Zhang, J.; Zheng, B.; Zhang, C.; Wen, X.; Li, N.; Huang, F. Org. Biomol. Chem. 2008, 6, 2103.

93. Orita, A.; Okano, J.; Uehara, G.; Jiang, L.; Otera, J. Bull. Chem. Soc. Jpn. 2007, 80, 1617.

94. Wang, F.; Zhou, Q.; Zhu, K.; Li, S.; Wang, C.; Liu, M.; Li, N.; Fronczek, F. R.; Huang, F. Tetrahedron 2009, 65, 1488. 
95. Li, S.; Liu, M.; Zhang, J.; Zheng, B.; Wen, X.; Li, N.; Huang, F. Eur. J. Org. Chem. 2008, 6128.

96. Zhang, J.; Huang, F.; Li, N.; Wang, H.; Gibson, H. W.; Gantzel, P.; Rheingold, A. L. J. Org. Chem. 2007, 72, 8935.

97. Niu, Z.; Slebodnick, C.; Schoonover, D.; Azurmendi, H.; Harich, K.; Gibson, H. W. Org. Lett. 2011, 13, 3992.

98. Niu, Z.; Slebodnick, C.; Bonrad, K.; Huang, F.; Gibson H. W. Org. Lett. 2011, 13, 2872.

99. Niu, Z.; Slebodnick, C.; Huang, F.; Azurmendi, H.; Gibson, H. W. Tetrahedron Lett. 2011, $52,6379$.

100. Zhao, J.-M.; Zong, Q.-S.; Han, T.; Xiang, J.-F.; Chen, C.-F. J. Org. Chem. 2008, 73, 6800.

101. Tachibana, Y.; Nakazono, K.; Takata, T. Supramol. Chem. 2012, 5, 2207.

102. Rescifina, A.; Chiacchio, U.; Corsaro, A.; Romeo, G. Curr. Org. Chem. 2012, 16, 127.

103. Belowich, M. E.; Stoddart, J. F. Chem. Soc. Rev. 2012, 41, 2003.

104. Dasgupta, S.; Wu, J. Chem. Sci. 2012, 3, 425.

105. Jiang, W.; Nowosinski, K.; Loew, N. L.; Dzyuba, E. V.; Klautzsch, F.; Schaefer, A.; Huuskonen, J.; Rissanen, K.; Schalley, C. A. J. Am. Chem. Soc. 2012, 134, 1860.

106. Choudhary, U.; Northrop, B. H. Org. Lett. 2012, 14, 2082.

107. Yu, G.; Suzaki, Y.; Abe, T.; Osakada, K. Chem. Asian J. 2012, 7, 207.

108. Ebadi, A. G.; Alami, S. Appl.Mech.Mater. 2012, 110.

109. Took, Ch.; Frey, J.; Sauvage, J. P. In Molecular Switches 2nd. Ed., 2011, B. L. Feringa, W. R. Browne Eds., Wiley-VCH: Weinheim, Vol. 2, 97.

110. Omori, K.; Takashima, Y.; Yamaguchi, H.; Harada, A. Chem. Lett. 2011, 40, 758.

111. Terao, J.; Kimura, K.; Seki, S.; Fujihara, T.; Tsuji, Y. Chem. Commun. 2012, 48, 1577.

112. Kiguchi, M.; Nakashima, S.; Tada, T.; Watanabe, S.; Tsuda, S.; Tsuji, Y.; Terao, J. Small 2012, 8, 726.

113. Araki, J.; Ohkawa, K.; Uchida, Y.; Murakami, Y. J. Polym. Sci. 2012, 50, 488.

114. Zalewski, L.; Mativetsky, J.M.; Brovelli, S.; Bonini, M.; Crivillers, N.; Breiner, T.; Anderson, H. L.; Cacialli, F.; Samori, P. Small 2012, 8, 1835.

115. Han, C.; Yu, G.; Zheng, B.; Huang, F. Org. Lett. 2012, 14, 1712.

116. Ma, Y.; Chi, X.; Yan, X.; Liu, J.; Yao, Y.; Chen, W.; Huang, F.; Hou, J.-L. Org. Lett. 2012, $14,1532$.

117. Koyama, Y.; Suzuki, Y.; Asakawa, T.; Kihara, N.; Nakazono, K.; Takata, T. Polym. J. 2012, 44, 30.

118. Hu, J.; Hashidzume, A.; Harada, A. Macromol. Chem. Phys. 2011, 212, 1032.

119. Qian, H.; Guo, D.-S.; Liu, Y. Chem. Eur. J. 2012, 18, 5087.

120. Motoyama, K.; Hayashida, K.; Higashi, T.; Arima, H. Bioorg. Med. Chem. 2012, 20, 1425. 


\section{Authors' Biographies}

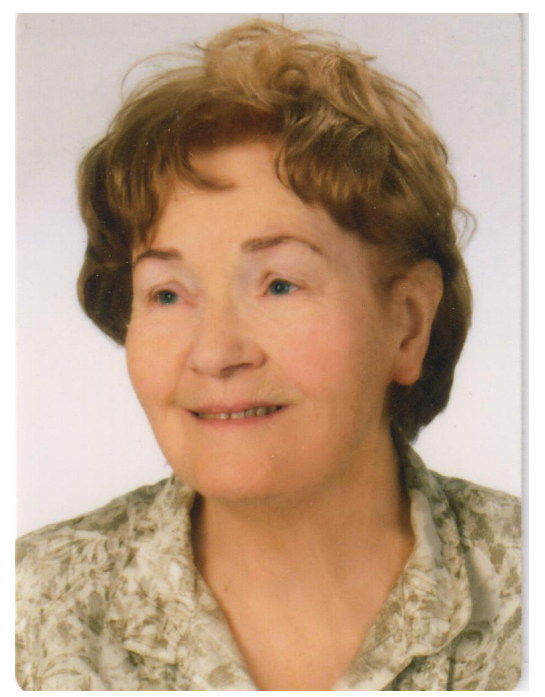

Wanda Sliwa graduated from Wrocław University of Technology, Poland where she became an associate professor. After a year research at Université Paul Sabatier a Toulouse, France, she moved to Jan Dlugosz University of Czestochowa, Poland, where she has been Professor of Chemistry since 1990, as well as being a vice-rector, head of the Organic Chemistry Department and director of the Institute of Chemistry. She is author or coauthor of four books and 16 monographs, around 350 papers and ten patents, and has received several awards for scientific and pedagogical achievements. Her research concerns azaaromatic compounds and supramolecular chemistry.

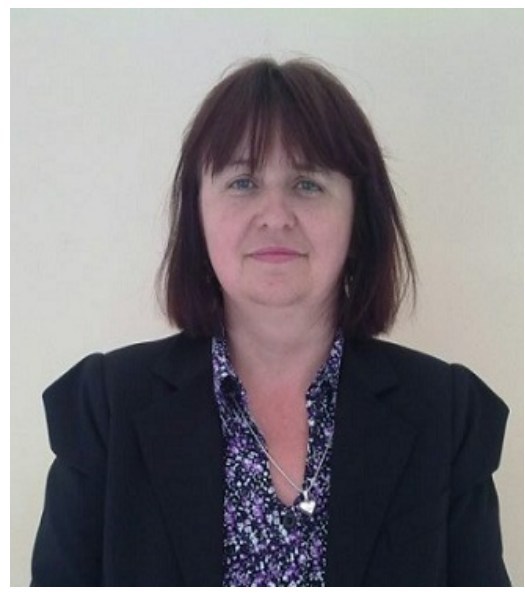

Malgorzata Deska graduated from Pedagogical University of Częstochowa, Poland, she received there M.Sc. degree in 1990. Since this time she works at Jan Długosz University (formerly Pedagogical University) of Częstochowa in Organic Chemistry Department and in 
Biochemistry Department. In 2004 she obtained her PhD at Technical University of Krakow, the doctor thesis concerned physicochemical properties of diazaphenanthrenes. She has published 15 papers in refereed journals, 5 communications to scientific meetings and is a coauthor of a book. The research interests of Dr Malgorzata Deska are connected with chemistry of heterocyclic compounds, cyclodextrins and calixarenes.

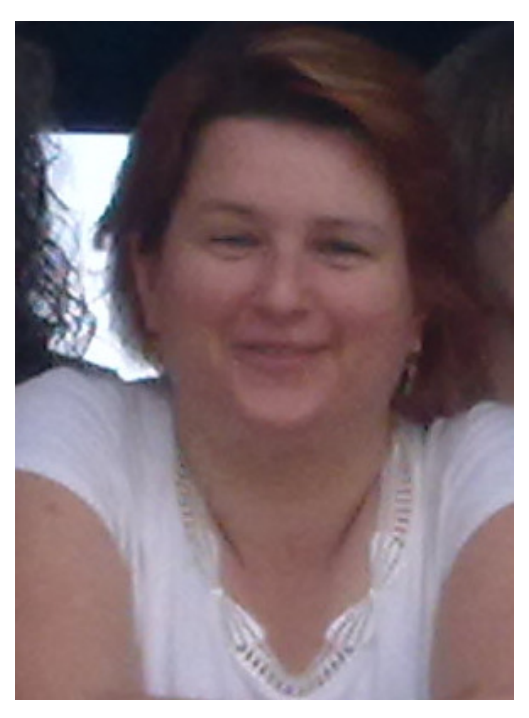

Jolanta Kozlowska graduated from Pedagogical University of Czestochowa, Poland and received there the Chemistry M.Sc. degree in 1997. In 2000 she obtained the Mathematics M.Sc. degree at Opole University (Poland).She works at Jan Dlugosz University (formerly Pedagogical University) of Czestochowa, in Institute of Chemistry, Environment Protection and Biotechnology. Dr. Jolanta Kozlowska obtained PhD at Technical University of Wroclaw; her doctor theme concerned membrane processes with the use of macrocycles. She is coauthor of 16 papers in refereed journals, and of 20 conference communications. Her research is connected with application of membrane technics in separation of metal ions. 